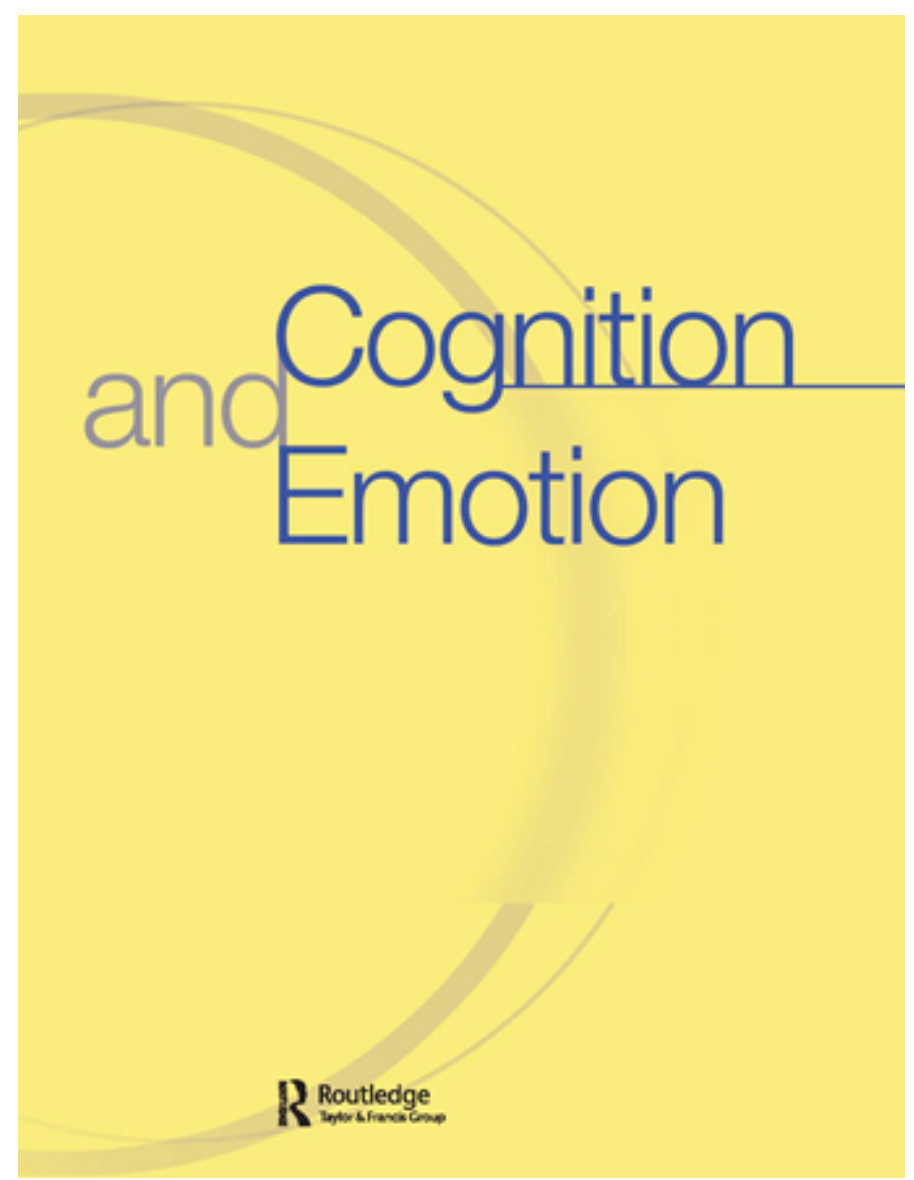

\title{
My Emotions Belong Here and There: Extending the Phenomenon of Emotional Acculturation to Heritage Culture Fit.
}

\begin{tabular}{|r|l|}
\hline Journal: & Cognition and Emotion \\
\hline Manuscript ID & CEM-FA 165.18.R2 \\
\hline Manuscript Type: & Full Article \\
\hline Author: & n/a \\
\hline Complete List of Authors: & $\begin{array}{l}\text { De Leersnyder, Jozefien; KU Leuven, Department of Psychology } \\
\text { Kim, Heejung; University of California, Santa Barbara, Department of } \\
\text { Psychological and Brain Sciences } \\
\text { Mesquita, Batja; KU Leuven, Department of Psychology }\end{array}$ \\
\hline Keywords: & $\begin{array}{l}\text { emotional acculturation, emotion, culture, acculturation, cultural frame } \\
\text { switching, cultural fit }\end{array}$ \\
\hline &
\end{tabular}




\section{SCHOLARONE ${ }^{\text {W }}$ Manuscripts}


RUNNING HEAD: EMOTIONAL FIT WITH THE HERITAGE CULTURE

Submitted to: Cognition and Emotion

My Emotions Belong Here and There:

Extending the Phenomenon of Emotional Acculturation to Heritage Culture Fit.

\author{
Jozefien De Leersnyder \\ University of Leuven \\ Heejung S. Kim \\ University of California, Santa Barbara \\ Batja Mesquita \\ University of Leuven
}

Words: 9855

\begin{abstract}
Author's Note
Jozefien De Leersnyder \& Batja Mesquita, Center for Social and Cultural Psychology, University of Leuven; Heejung Kim, Department of Psychological and Brain Sciences, University of California Santa Barbara.

This research was supported by research funds from the University of Leuven to the last author and by an FWO post-doctoral grant that was awarded to the first author (grant number: 12L7816N).

Correspondence concerning this article should be addressed to Jozefien De Leersnyder or Batja Mesquita, Center for Social and Cultural Psychology, Tiensestraat 102, bus 3727, 3000 Leuven, Belgium. Email: Jozefien.DeLeersnyder@kuleuven.be; mesquita@kuleuven.be

We thank Berna Coker and her colleagues from the Buça Eğitim Facultesi at the Doküz Eylül Üniversitesi in Izmir and Joke Van Eylen for their support during our data-collection in Turkey. We also thank Kimin Eom and Hyewon Choi for collecting the data in Korea.

The data and SPSS-syntax that support the findings of these studies are available from the corresponding author, [JDL], upon reasonable request.
\end{abstract}


RUNNING HEAD: EMOTIONAL FIT WITH THE HERITAGE CULTURE

\begin{abstract}
When immigrant minorities engage in a new cultural context, their patterns of emotional experience come to change - a process we coined emotional acculturation (De Leersnyder, Mesquita, \& Kim, 2011). To date, research on emotional acculturation focused on the antecedents and consequences of changes in minorities' fit with the new culture. Yet, most minorities also continue to engage in their heritage culture. Therefore, the current research investigated which personal and situational factors afford minorities to maintain emotional fit with their heritage culture. Two studies compared the emotional patterns of Korean Americans $(n=49)$ with those of Koreans in Korea $(n=80)$, and the emotional patterns of Turkish Belgians ( $n=144)$ with those of Turks in Turkey $(n=250)$, respectively. As expected, we found that although minorities did not fit the heritage emotional patterns as well as participants in their home countries, spending time with heritage culture friends and interacting in heritage culture settings explained within-group differences in minorities' heritage culture fit. Therefore, the current research shows that minorities' emotional patterns are not only cultivated, but also activated by their interactions in different socio-cultural contexts. Moreover, it provides further evidence for cultural frame-switching in the domain of emotion.
\end{abstract}

Words: 200

Keywords: Emotional acculturation; emotion; culture; acculturation; cultural frame switching, cultural fit 
RUNNING HEAD: EMOTIONAL FIT WITH THE HERITAGE CULTURE

\section{My Emotions Belong Here and There:}

\section{Extending the Phenomenon of Emotional Acculturation to Heritage Culture Fit.}

Emotional acculturation refers to the process of changes in one's emotional life that are due to sustained contact with another culture (De Leersnyder, 2017). Indeed, the more immigrant minorities engage in a new culture, the more their patterns of emotion come to fit with the typical patterns of that culture (Consedine, Chentsova-Dutton, \& Krivoshekova, 2014; De Leersnyder, Mesquita, \& Kim, 2011; Jasini, De Leersnyder, Phalet, \& Mesquita, 2019) - fit that is positively associated with well-being (Consedine et al., 20014; De Leersnyder, Kim, \& Mesquita, 2015; De Leersnyder, Mesquita, Kim, Eom, \& Choi, 2014). However, since many (if not most) immigrant minorities not only engage in their new socio-cultural environment, but also continue to be part of social networks and communities that represent their heritage culture (van den Broek \& van Ingen, 2008), emotional acculturation may not only pertain to adopting a new culture's emotional patterns, but also to preserving one's heritage culture's patterns.

To date, no studies have investigated minorities' emotional fit with their heritage culture. Therefore, the current research addresses which personal and situational factors foster Korean Americans (Study 1) and Turkish Belgians (Study 2) to maintain their heritage culture's emotional patterns. As personal factors, we investigated which specific aspects of minorities' engagement in the heritage culture predict their heritage culture emotional fit. Is it a matter of having been exposed to the heritage cultural context? Or rather a matter of having heritage culture friends? As situational factor, we tested if the cultural setting of interaction matters for emotional fit. Do minorities have a higher fit with heritage emotional patterns when they interact in heritage culture settings, such as at home?

By addressing these questions, the current research aims to contribute to our understanding of emotional acculturation as a multi-dimensional and context-dependent process of emotional adaptation. Simultaneously, it aims to contribute to our understanding of 
emotion itself. For instance, if we were to find that minorities' emotional fit with their heritage culture is a function of their heritage culture engagement, this would provide further support for the idea that people's cultural engagements shape their emotional experiences (Mesquita, 2003; Mesquita, Boiger, \& De Leersnyder, 2017). Furthermore, if minorities would fit heritage emotional patterns better in heritage culture settings, this would suggest that people construct their emotional experiences 'in the moment' to be in line with the prevailing cultural context (Boiger \& Mesquita, 2012; Mesquita, Boiger, \& De Leersnyder, 2016).

\section{Cultural differences in emotional patterns}

The main starting point for research on emotional acculturation are the well-documented and systematic cultural differences in people's emotional experiences (Kitayama, Mesquita, \& Karasawa, 2006; Mesquita, 2003; Tsai, Knutson, \& Fung, 2006). For instance, experiences like pride, anger, or irritation that afford autonomy and independence and that have been called socially disengaging or autonomy-promoting emotions (De Leersnyder, Koval, Kuppens, \& Mesquita, 2018) tend to be most prevalent and intense in cultural contexts that value independence and autonomy, such as European American middle class contexts. In contrast, experiences like feeling close, ashamed or indebted that encourage relatedness and interdependence and that have been called socially engaging or relatedness-promoting emotions, tend to be most prevalent and intense in cultural contexts that value interdependence and relatedness, such as in Japanese and Mediterranean contexts (e.g., Boiger, Mesquita, Uchida, \& Barrett, 2013; Boiger, Güngör, Karasawa, \& Mesquita, 2014; Kitayama et al., 2006; Markus \& Kitayama, 1991; Rothbaum, Pott, Azuma, Miyake, \& Weisz, 2000). Thus, emotions that match a culture's central goals and values tend to be experienced more frequently and intensely than emotions that do not.

Building on these findings, we may expect that different cultural contexts are characterized by different 'typical' patterns of emotional experience and that individuals who 
engage in the same cultural context - and, therefore, are exposed to the same meanings and practices - experience more similar patterns of emotion than people who engage in different cultural contexts. Furthermore, we may expect that the emotional patterns of immigrant minorities may be initially different from those that are typical for their new majority culture, yet come to be aligned with them upon increased engagement in the majority culture - that is, that people's emotional patterns may acculturate.

\section{Emotional acculturation towards the new majority culture patterns of emotion}

There is now strong evidence for emotional acculturation, with several large scale studies on different minority groups in both the United States and Belgium that documented that minorities' engagement in a new cultural context is positively associated with their emotional fit to that context (Consedine et al., 2014; De Leersnyder et al., 2011; Jasini et al., 2019). Firstly, whereas first generation immigrants had significant lower emotional fit with the majority culture than majority members themselves, fit levels seemed to increase for each later generation. This finding was most outspoken for negative situations and resonates with the general observation that emotional fit tends to be higher in (typically more straightforward) positive than in (typically more complex) negative situations (see De Leersnyder et al., 2011 for a discussion on this issue).

Secondly, minorities' emotional fit (in both positive and negative situations) was higher to the extent they were more exposed to the majority culture (i.c. were younger at the time of migration; have spent more years) and had more social interactions with majority members. Zooming in on this latter link, a recent large-scale social network study on immigrant minority youth showed that although their emotional fit with the majority was predicted by both outgoing and incoming ties with majority peers, it was most strongly predicted by bi-directional ties, which signal reciprocity and thus 'true friendship' (Jasini, De Leersnyder, Kende, et al., submitted). This latter finding suggests a potential special function of close friends in learning 
and maintaining emotional patterns: It is perhaps in the (safe and open) context of friendships that people mostly share emotional episodes with one another and that they get reinforced or questioned about the meanings and experiences they associate with these episodes.

Finally, minorities' emotional fit with the majority culture was unrelated to their attitudes towards adopting the majority culture's values and traditions (De Leersnyder et al., 2011; Jasini, et al., 2019). Though counterintuitive at first sight, this finding is in line with the ideas that i) "explicit beliefs [attitudes] may be quite independent of implicit psychological tendencies [emotions]" (Kitayama \& Imada, 2010, p. 186), and that ii) different domains may acculturate at a different pace or even in different directions (Mesquita, De Leersnyder, \& Jasini, 2019; Schwartz, Unger, Zamboanga, \& Szapocznik, 2011; Snauwaert, Soenens, Vanbeselaere, \& Boen, 2003). Taken together, past research thus suggests that minorities' emotional fit with the typical majority patterns is a function of their actual rather than their desired engagement in the majority culture.

\section{Emotional acculturation and heritage culture patterns of emotion}

Notwithstanding the importance of minorities' fit with the majority culture, we may not lose sight of the potential multi-dimensional nature of the emotional acculturation process. As mentioned above, most immigrant minorities not only engage in majority contexts, but continue to engage in heritage contexts on a daily basis, be it through family members, friends, or the ethnic composition of their neighbourhood (van den Broek \& van Ingen, 2008). If emotional experiences, then, are a function of socio-cultural engagements, both majority and heritage culture engagement should shape emotional patterns. Moreover, and grounded in research that showed minorities' potential for simultaneous endorsement of positive attitudes towards both the majority and heritage cultures (Berry, 1997; Ryder, Alden, \& Paulhus, 2000), it may well be that they can come to fit the emotional patterns of the new majority culture without losing fit with the heritage culture. If so, minorities may furthermore alternate between majority and 
RUNNING HEAD: EMOTIONAL FIT WITH THE HERITAGE CULTURE

heritage emotional patterns depending on their context of interaction, just like they do in the domains of identity and cognition (e.g., LaFromboise, Coleman, \& Gerton, 1993; Hong, Morris, Chiu, \& Benet-Martinez, 2000). Thus, to gain insight into the (complexities of the) process of emotional acculturation, it may be fruitful to study minorities' heritage culture fit and, more specifically, to identify both the personal and situational factors that foster this fit.

Personal factors. To identify personal factors associated with minorities' heritage culture fit, we build on the studies on majority culture fit reviewed above. Firstly, we expect group differences in people's emotional fit to the heritage culture (H1), such that this is highest for majority members living in the home country (i.c., Koreans in Korea, Turks in Turkey), lowest for majority members from the new majority context who are unlikely to have spent time in minorities' home country (i.c., European Americans and Belgians), and somewhere 'in between' for immigrant minority groups, with first generation minorities having slightly higher fit to the heritage culture than later generation minorities.

Secondly, we expect that minorities' heritage culture fit is positively associated with their direct exposure to the heritage culture (H2) as measured by i) the number of years spent in the heritage culture and ii) the percentage of time spent in the heritage versus new majority context.

Thirdly, we expect that minorities' emotional fit with the heritage culture is a function of their social contacts with heritage culture members (H3) as measured by composite scores of i) the number of colleagues, friends and neighbours that have a heritage cultural background, (which is a direct index of the ethnicity of one's social contacts), and/or ii) whether one speaks one's heritage language with family members, colleagues, friends, neighbours, etc., (which is an indirect index of whether one interacts with heritage versus majority culture members).

Finally, we expect that minority members' explicitly formulated attitudes towards the heritage cultural values and traditions will not predict heritage culture fit (H4), because 
RUNNING HEAD: EMOTIONAL FIT WITH THE HERITAGE CULTURE

emotional fit - as a rather implicit measure of minorities' cultural affiliation - may change at a different pace, or even in a different direction, than explicitly endorsed attitudes.

However, since most immigrant minorities live in ethnic enclaves, and the participants of this research were no exception to this, we may think of two alternative hypotheses that do not mirror the findings on majority culture fit. Firstly, since ethnic enclaves expose their residents to (a form of) heritage cultural ideas and practices on a daily basis, the time or proportion spent in the country of origin may not substantially add to minorities' exposure to the heritage culture (H2A). Secondly, minority groups may be very homogenous in the extent to which they have contact with heritage culture family members, colleagues and neighbours, which lowers their predictive value. Therefore, only social contact with heritage culture friends, which already have a special status in relation to (re)shaping emotional experience (Jasini, et al., submitted), may be the best (if not the only) personal factor predicting heritage culture emotional fit (H3A). The current research will explore which one of these two sets of hypotheses fit the data best.

Situational factor. The second aim of this research is to test if immigrant minorities' emotional patterns depend on the situation and, more specifically, the socio-cultural context in which they are experienced. Indeed, biculturals may display different psychological tendencies and behaviours when being primed with their heritage versus new majority culture - a phenomenon that is commonly referred to as cultural frame switching (Hong, Morris, Chiu, \& Benet-Martínez, 2000) and that has been extensively documented in various psychological domains (e.g., Hong et al., 2000; Ramírez-Esparza, Gosling, Benet-Martínez, Potter, \& Pennebaker, 2006; Briley, Morris, \& Simonson, 2005), except for emotion. In fact, evidence is limited to one study (Perunovic, Heller, \& Rafaeli, 2007) showing that East Asian Canadians' momentary positive and negative moods were less (rather than more) negatively correlated after having spoken an Asian language or having identified with their heritage culture, which is in 
line with an Asian (rather than Western) dialectical emotional style. Therefore, we hypothesize that when minorities report emotional patterns that took place in heritage culture settings, like one's home, these will be more concordant to the typical heritage cultural patterns than those that were experienced in majority settings, like one's school or workplace (H5).

\section{Current studies}

Data. To investigate the above outlined hypotheses, we extend previous research on immigrants' adoption of the new culture's emotional patterns (De Leersnyder et al., 2011), by studying the same immigrant groups in terms of their maintenance of heritage culture emotional patterns. These previous studies focused on (mainly first generation) Korean Americans (Study 1) and first and second generation Turkish Belgians (Study 2), each time comparing their emotional patterns to those of their respective majority cultural groups (European Americans and Belgians). In the current research, we collect new data to compare minorities' emotional patterns to those of their heritage cultural groups, i.e. Korean and Turkish majority members in Korea and Turkey, respectively. Hence, the here reported analyses are novel and in no sense similar to what we have analysed and reported in previous work.

Cultural groups under study. We chose the target minority and majority groups on the basis of two criteria. First, and to maximize the prospect of observing acculturative shifts in minorities' emotional patterns, we chose majority and minority groups that differ in their typical emotional patterns (see Kitayama et al., 2006; Mesquita, 2001). Second, and to maximize the potential for analytic inference from these case studies to a more general theory on emotional acculturation, we selected two minority groups that are very different in their socio-economic statuses, migration histories and diversity contexts. ${ }^{1}$ Hence, Study 1 and Study 2 are theoretical

\footnotetext{
${ }^{1}$ Korean Americans are more highly educated and better employed than Turkish Belgians (FOD Werkgelegenheid, 2009; Terrazas, 2009) and face a racial rather than a religious 'divide' whereas the opposite is true for Turkish Belgians (Alba, 2005; Yoo \& Chung, 2009). Moreover, both groups navigate very different
} 
replications of one other, enabling us to be more confident in drawing conclusions about the personal and situational factors that afford minorities to maintain their heritage culture patterns of emotion.

\section{Study 1}

Study 1 was designed to test our hypotheses in a sample of Korean Americans. To calculate their emotional concordance to their heritage culture's typical patterns of emotional experience, we collected data from Koreans in South Korea.

\section{Method.}

Participants. Participants were 49 Korean Americans, of whom 37 were first generation immigrants who had spent about half of their lives in Korea $\left(M_{\text {proportion_life_Korea }}=0.54, S D=\right.$ 0.34), and 44 European Americans; both were available from earlier research (De Leersnyder et al., 2011). For the purpose of this research, we additionally sampled 80 Koreans living in South Korea. The three samples were comparable in terms of self-reported social class, education and gender composition (See Online Supplementary Materials for full statistics), but Koreans were younger $\left(M_{\text {age }}=27.9 ; S D_{\text {age }}=4.3\right)$ than both Korean Americans $\left(M_{\text {age }}=38.2\right.$; $S D_{\text {age }}=12.8 ;$ Mdiff $\left.=-10.317 ; t_{(50.96)}=-5.280, p \leq .001\right)$ and European Americans $\left(M_{\text {age }}=37.6\right.$; $S D_{\mathrm{age}}=16.6 ;$ Mdiff $\left.=-9.762 ; t_{(43.95)}=-3.741, p=.001\right)$.

Controlling for Gender, Age, Class, or Educational Attainment did not alter the results. Yet, in order to keep the current series of analyses consistent with those on minorities' adoption of new majority emotional patterns, (De Leersnyder et al., 2011), we excluded one Korean American who had received none or only primary education and controlled for Educational Attainment in our analyses (dummy coded as $0=$ "secondary education"; $1=$ "tertiary education"). We further excluded two Korean Americans who failed to report situations that 
RUNNING HEAD: EMOTIONAL FIT WITH THE HERITAGE CULTURE

matched the valence of the prompts, which prevented us from calculating their emotional fit (see below).

Materials. Emotional Patterns Questionnaire (EPQ). To capture people's emotional fit with culture, we administered the EPQ (De Leersnyder et al., 2011), which asks participants to describe a recently experienced emotional situation that matches a prompt. Prompts vary on the dimensions of valence (positive vs. negative), social engagement (socially disengaging/autonomy-promoting vs. socially engaging/relatedness-promoting) and relational context (home/family vs. work/school). For example, the prompt for positive disengaging situations in work/school contexts read: "Please think about an occasion at work or at school in which you felt good for yourself. For example, you felt superior, proud, top of the world”. After describing such a situation, participants were asked to rate the intensity (from $1=$ "Not at all" to $7=$ "Extremely") of their experience in that situation on a set of 20 emotion scales that cover the emotional domain in terms of valence and social engagement (see Online Supplementay Materials Table 1A). These data constitute a participant's emotional pattern for a given situation.

To calculate emotional fit with the heritage culture, we took the following steps. Firstly, we removed three emotion items from participants' emotional patterns because a Simultaneous Component Analysis (De Roover et al., 2012) had indicated that only the 17 other items were structurally equivalent across Korean and European American samples (see De Leersnyder et al., 2011 for full results). ${ }^{2}$ Secondly, we established the average Korean emotional patterns for

\footnotetext{
${ }^{2}$ In both Study 1 and Study 2 we employed a Simultaneous Component Analysis (SCA; De Roover et al., 2012) to assess structural equivalence of the emotion data. This analysis provides insight into i) whether one common factor solution can be used across the different samples under study and ii) which items load on different factors, implying that they are not structurally equivalent and hence, differently understood across the cultural groups. For instance, in Study 2, "feeling resigned" loaded on the negative autonomy-promoting emotion component in the
} 
each type of prompt (e.g., for positive autonomy-promoting situations at work/school) by averaging the emotion ratings from all Korean majority members who had responded to that prompt. As such, we obtained eight different Korean average patterns of emotion, one for each type of prompt. Thirdly, we calculated Korean American's and European Americans' emotional concordance or fit to the average Korean patterns by correlating each individual's pattern to the corresponding (i.e., same situation-type) Korean average pattern. To calculate Korean majority members' fit with their own culture's average patterns, we correlated each individual's pattern of emotion to a pattern that consisted of all other Koreans' scores and thus excluded the participants own score from the average. In this way, we avoided an artificial inflation of Koreans' concordance scores; individuals' patterns are never correlated to an average pattern they have contributed to themselves. Fourthly, we transformed all correlation scores into Fisherz scores to ensure linearity, which is required for further analyses.

Finally, we aggregated participants' Fischer z-scores to obtain one mean emotional concordance variable. However, because of logistical reasons, Korean majorities completed four versions of the EPQ, with each prompt pertaining to a different type of valence*engagement within the same relational context (either home/family $(n=40)$ or work/school $(n=40))$, whereas Korean Americans and European Americans had completed two versions of the EPQ, with prompts that pertained to same type of valence*engagement, but differed across relational contexts (i.e., one in a work/school context; the other in a home/family

Belgian sample, but loaded on both the negative autonomy-promoting and the positive relatedness-promoting components in the Turkish Belgian samples. Personal conversations with Turkish Belgian participants explained that "resigning" can be understood as embracing "kismet" (i.e., the Turkish concept of faith), which has a positive connotation in the Turkish cultural context. Although these cultural differences are interesting in itself, we removed items like this from the emotional patterns before calculating 'fit', because any (cultural) difference in intensity on these items may be due to their different meaning, while 'fit' is about the (cultural) differences in patterns of intensity across emotions that have similar meanings across the groups under study. 
RUNNING HEAD: EMOTIONAL FIT WITH THE HERITAGE CULTURE

context). This implies that Korean majorities' overall emotional fit score was the average of four fit scores, whereas those of Korean Americans and European Americans was the average of only two.

Personal Factors of Cultural Engagement. Korean Americans' exposure to Korean culture was captured by the Number of Years and their Proportion of Life spent in the heritage culture. The scale capturing Korean Americans' degree of Social Contact with Heritage Culture Members consisted of three items $(\alpha=.74)$ that asked about the ethnicity of their friends, colleagues, and neighbors, respectively (on a scale from $1=$ "heritage culture only" to $5=$ "Euro-Americans only"). We recoded all items such that higher scores indicated more social contact with Koreans $(M=3.01(S D=0.88)$.

Korean Americans' acculturation attitudes were measured by 8 items from the Vancouver Index of Acculturation (Ryder et al., 2000), with scales ranging from 1 (totally disagree) to 9 (totally agree). A Principal Component Analysis yielded two different factors that formed the basis of two scales: Attitudes toward the Maintenance of Values and Traditions (four items, $\alpha=.78 ; M=6.28, S D=1.55$; Example: "It is important for me to maintain or develop Korean cultural practices") and Attitudes toward Social Contacts with Heritage Culture Members (four items, $\alpha=.77 ; M=7.29, S D=1.35$; Example: "I am interested in having Korean friends"). The two scales were significantly correlated with each other $(r=.523, p \leq .001)$.

Situational factor of Cultural Engagement: Our situational factor is the socio-cultural context in which the situation took place (as specified by the prompt): either at home/with family versus at work/school. We consider the home/family context as representative for the heritage culture since most minorities have family members with a heritage culture background, and consider the work/school context as representative for the new majority culture since most of minorities' colleagues/classmates have a majority cultural background. 
Procedure. Before participating, participants received, read, and signed an informed consent (approval granted by the Human Subjects Committee, University of California at Santa Barbara). Korean Americans and European Americans had been recruited in public places, such as malls, churches, and coffee shops in Southern California, where Korean Americans live in immigrant neighbourhoods (see De Leersnyder et al., 2011). Koreans in Korea were recruited through a Christian mega-church because $91 \%$ of Korean Americans self-identify as Christians (Yoo \& Chung, 2009) and we wanted the Korean sample to be similar in this regard. Korean participants received $\$ 10.000$ (about \$10) for completing the questionnaires in Korean.

\section{Results.}

Analytic strategy. To assess how personal factors were associated with heritage culture emotional fit (i.e., to test H1-H4), we made use of participants' aggregated emotional fit scores with the Korean typical patterns of emotion. To test group differences in participants' emotional fit (H1), we conducted an ANOVA that predicted all participants' fit score from their group membership. To test if minorities' emotional fit with the Korean patterns was predicted by their exposure (H2) or not (H2A) and general level of social contact with Koreans (H3) versus only by the number of heritage culture friends (H3A), we conducted a carefully planned series of hierarchical linear regression analyses. The dependent variable was always Korean Americans' fit with the typical Korean patterns of emotion, yet separate regressions were run for each 'predictor of interest', resulting in 4 different analyses to test the 4 main hypotheses (i.e., Regression 1: Number of Years in Korea; Regression 2: Proportion of Life in Korea; Regression 3: Social Contact Koreans; Regression 4: Acculturation Attitudes; see also Table 1) and 3 additional ones to test H3A. The first two blocks of each regression included our control variables, namely Valence and Engagement as the between-subject variables in our design (Block 1) and Educational Attainment (Block 2). Block 3 always included our predictor of interest. Whereas Block 4 tested all two-way interactions between the specific predictor of 
interest (as entered in Block 3) and Valence and Engagement, Block 5 did so for the two way interaction between the predictor of interest and Educational Attainment. Finally, Block 6 tested the 3-way interaction between the specific predictor of interest, Valence, and Engagement.

To assess the influence of the situational factor on heritage culture emotional fit (H5), which requires to compare Korean Americans' fit with the Korean versus the European American average patterns of experience, we relied on Korean Americans' fit scores with both the average Korean patterns and those with the average European American patterns established in previous work (De Leersnyder et al., 2011). Moreover, because this hypothesis requires a comparison at the level of the relational context (home/with family vs. work/school) and this was a within-subjects factor, we used participants' unaggregated fit scores. Specifically, we ran two paired-samples t-tests (one for home/family context; the other for work/school context) that each time compared Korean Americans' fit with the typical Korean pattern to their fit with the typical European American pattern.

Personal factors: Which aspects of heritage engagement predict Korean Americans' heritage emotional fit? At the group level, we had hypothesized that emotional fit to the typical Korean patterns would be higher for the Korean majority group than the Korean American and European American groups (H1). Consistently, an ANOVA yielded group differences in mean emotional fit $\left(F_{(2,163)}=16.698 ; p \leq .001, \eta^{2}=.170\right)$. Pairwise comparisons showed that Koreans in Korea fitted the typical Korean pattern significantly better $(M=1.05$; $S D=.28)$ than European Americans $\left(M=.63 ; S D=.50 ; M_{\text {diff }}=.42 ; p \leq .001,95 \%\right.$ CI: $[.263$, $573])$ and Korean Americans $\left(M=.74 ; S D=.50 ; M_{\text {diff }}=.31 ; p \leq .001,95 \%\right.$ CI: [.156, .459]). The fit scores of Korean Americans fell nicely in between those of Koreans and European Americans, yet were not significantly higher than those of European Americans (see Figure 1, left panel). 
At the individual level, we explored the two contrasting sets of hypotheses outlined in the Introduction. On the one hand, we had hypothesized that engagement in the heritage culture would predict heritage emotional fit $(\mathrm{H} 2 \& \mathrm{H} 3)$; on the other hand, the alternative hypotheses stated that the operationalisations of cultural exposure (number of years and proportion of life spent in heritage culture) would not be associated with immigrants' emotional fit (H2A) and that fit would be only predicted by one's number of Korean friends (H3A).

As described above, we tested these predictions by conducting a series of four hierarchical linear regressions to test $\mathrm{H} 2-\mathrm{H} 4$ and three additional ones to test $\mathrm{H} 3 \mathrm{~A}$. All regressions yielded a main effect of Valence (step $1 R^{2}$ change $=.369, p \leq .001 ; B$ 's ranging from -.615 to $-.580, p \leq .001$; see Table 1 , panel A), indicating that participants had significantly higher emotional fit in positive than in negative situations. The other control variables (Block 1: Engagement; Block 2: Educational attainment) did not significantly contribute to explaining variance in immigrants' Korean emotional fit, and Blocks 5 and 6 that tested all two-way and three-way interactions never yielded significant results; hence, we don't report them here (full results can be obtained from the first author).

Regressions 1 and 2 showed that Korean Americans' emotional fit to Korean patterns was neither associated with the number of years nor with the proportion of life spent in Korea (all $p>.10$; for the full results, see Table 1, panel A, Regressions 1 and 2), which renders support for $\mathrm{H} 2 \mathrm{~A}$ instead of $\mathrm{H} 2$. For minorities in ethnic enclaves (such as the ones we recruited), time spent in the heritage country does not predict heritage emotional fit, perhaps because it does not expose minorities to heritage culture's meanings and practices above and beyond what they are exposed to in their ethnic minority communities in their country of residence.

Regression 3, testing the link between heritage culture fit and social contact with heritage culture members, showed that general social contact was not predictive of emotional fit (step $3 R^{2}$ change $=.005, p=.592$, see Table 1, panel A, Regression 3 ). To test the alternative 
RUNNING HEAD: EMOTIONAL FIT WITH THE HERITAGE CULTURE

hypothesis (H3A) that only the number of Korean friends matters, we first ran Regression 3bis that included the item on having Korean friends as the predictor of interest and then another two analyses that included the item on having Korean colleagues and Korean neighbours, respectively. Confirming hypothesis $3 \mathrm{~A}$, only having Korean friends contributed significantly to Korean Americans' heritage emotional fit, be it that this effect was moderated by Valence (step $4 R^{2}$ change $=.132, p=.016, B_{\text {Valence*KoreanFriends }}=.372, p=.015,95 \%$ CI $[.076, .669]$, see Table 1, panel A, Regression 3bis). This effect was still significant after applying Bonferroni corrections for multiple comparisons $\left(p=.015<\alpha_{.05 / 3}=.017\right)$. Simple slopes indicated that the number of Korean friends was positively associated with Korean emotional fit in negative situations (simple slope $B=.208, S E=.114, p=.077,95 \%$ CI [-.023, .439]), but not in positive situations (simple slope $B=-.164, S E=, 141, p=.254,95 \%$ CI $[-.450, .122]$ ). Analyses on the number of Korean neighbours and colleagues yielded no significant results (for full results see Online Supplementary Materials, Table 2A, panel A). Supporting H3A, the only predictor of heritage culture emotional fit is thus Korean Americans' number of heritage culture friends.

In a final regression, we tested the association between Korean Americans' emotional fit with the heritage culture and the two scales that tap into their attitudes towards maintaining their heritage culture (H4). As expected, minorities' emotional fit was unrelated to their attitudes towards maintaining Korean values and traditions. However, their attitudes toward maintaining social contacts with Koreans did marginally contribute to the prediction of heritage emotional fit (see Table 1, panel A, Regression 4). To disentangle whether this is an effect of attitudes per se versus of actually having Korean friends, we conducted a post-hoc regression analysis in which both variables were the predictors of interest. It showed that whereas Korean Americans' Korean emotional fit was not predicted by their attitudes towards social contact (step $3 R^{2}$ change $\left.=.060, p=.166\right)$, it was by their actual number of Korean friends (step $4 R^{2}$ change $=.160, p=.028 ; B=.412, p=.007,95 \%$ CI [.122, .702]; see Table 1 , panel A). 


\section{Situational factor: Does interacting in Korean cultural settings afford Korean}

Americans to fit the Korean emotional patterns better? Based on the cultural frame switching literature, we had expected that minorities' interactions in home/family contexts would afford emotional experiences that fit the Korean typical patterns better than the European American ones (H5). Hence, we compared, for each context, minorities' fit to the typical European American and to the typical Korean emotional patterns by means of paired samples t-tests. For the home context, we found a marginally significant effect suggesting that Korean Americans' emotional patterns fitted better with the Korean $(M=.76, S D=.62)$ than European American patterns $\left(M=.66, S D=.56 ;\right.$ Mean_diff $=.10, S E_{\text {mean diff }}=.05, t_{(42)}=1.895, p=.065$; one-tailed $p=.033 ; 95 \%$ CI: $[-.006, .200])$. For the work/school context, however, no such difference occurred (Mean_diff $=-.01, S E_{\text {mean diff }}=.06, t_{(42)}=-.096, p=.924 ; 95 \%$ CI: [-.118, $.108]$ see Figure 2 left panel).

Post-hoc exploratory analyses suggested that the exact pattern of emotional fit levels was different for first versus second or later generation Korean Americans. Specifically, we repeated the t-tests described above, yet now for first and second or later generations separately. For the home context, we found that first generation Korean Americans fitted significantly better with the Korean $(M=.74, S D=.63)$ than European American patterns $(M=.60, S D=$ $.57 ;$ Mean_diff $=.15, S E_{\text {mean diff }}=.065, t_{(30)}=2.249, p=.032$; one-tailed $p=.016 ; 95 \% \mathrm{CI}$ : $[.013, .279])$, whereas there was no such difference for second or later generation Korean Americans (Mean_diff $=-.03, S E_{\text {mean diff }}=.062, t_{(11)}=-.488, p=.635 ; 95 \%$ CI: $\left.[-.169, .108]\right)$. In work/school contexts, however, there was a non-significant trend for later generation Korean Americans to fit better with the European American $(M=.98, S D=.49)$ than the Korean $(M=$ $.90, S D=.57)$ typical patterns $\left(\right.$ Mean_diff $=-.08, S E_{\text {mean diff }}=.087, t_{(10)}=-.947, p=.366 ; 95 \%$ CI: $[-.277, .112])$, but this was not the case among first generation minorities (Mean_diff $=.02$, $\left.S E_{\text {mean diff }}=.069, t_{(31)}=.306, p=.762 ; 95 \% \mathrm{CI}:[-.120, .162]\right)$. Given the small numbers of 
RUNNING HEAD: EMOTIONAL FIT WITH THE HERITAGE CULTURE

participants, and especially the small number of second or later generation minorities $(n=12)$, conclusions should be treated with extreme caution. Yet, these results provide some initial support for the idea that situational factors such as the context of the interaction shape minorities' emotional experiences, at least among first generation minorities.

\section{Study 2}

Study 2 was not only a replication of Study 1 in another group of minorities (Turkish) within a different host culture setting (Belgium), but also overcame several of its limitations. Concretely, Study 2 consisted of sizable samples of first and second generation minorities, which allows us to reliably compare them. Furthermore, Study 2 used a similar design of the EPQ for all groups, thereby ruling out possible design effects when comparing mean emotional fit scores across samples. Finally, in Study 2 minorities were prompted to report on two emotional situations that either occurred in the home context or in the work/school context, thereby ruling out the possibility that any evidence for emotional frame switching can be accounted for by a contrast-effect that occurs when minorities report on both contexts in the same questionnaire. All hypotheses were exactly the same as for Study 1.

\section{Method.}

Participants. Participants were 144 Turkish Belgian minorities (59 first generation; 85 second generation) and 79 Belgian majorities that were available from earlier research (De Leersnyder et al., 2011), as well as 250 Turkish majority students from the Döküz Eylül Universitesi in Izmir, Turkey, who were sampled for the purpose of this study. Across the samples there were significant differences in age, with Turkish students being significantly younger $(M=20.1, S D=1.47)$ than first generation $(M=34.1, S D=10.85)$ and second generation minorities $(M=25.59, S D=6.63)$ as well as majority Belgians $(M=31.38, S D=$ 8.67; all Mean diff were significant at $p \leq .001)$. Furthermore, the Turkish majority sample was characterized by a higher proportion of female participants $(67 \%$ females) than the other three 
samples (around 50\%; $\chi^{2}=10.338, p=.016$ ) and was less highly educated since none of the Turkish students held a tertiary education degree yet (see Online Supplementary Materials for full statistics).

However, controlling for Age, Gender, or Educational Attainment did not change the results. In order to keep them comparable to both Study 1 and our earlier work (De Leersnyder et al., 2011), we excluded three first generation minorities who had received none or only primary education and controlled for Educational Attainment in our analyses (dummy coded as $0=$ "secondary education"; 1 = "tertiary education"). We further excluded 17 participants who failed to report a situation that matched the valence of the prompts; the proportion did not differ across cultural groups $\left(\chi^{2}=2.052, p=.562\right.$; Excluded: Turkish majority $n=10$, Turkish Belgian first generation $n=2$, Turkish Belgian second generation $n=1$, Belgian majority $n=4$ ).

Materials. Emotional Patterns Questionnaire (EPQ). The EPQ used in Study 2 was identical to the one used in Study 1. However, participants from all groups now completed two versions of the EPQ that pertained to the same Relationship Context (either home/family or work/school) and Valence (either positive or negative), but differed in terms of Engagement. In order to calculate emotional fit scores, we followed the exact same procedure as in Study 1, yet now using the Turkish average emotional patterns as standard of reference with which we correlated individuals' patterns. Again, the correlations were based on only those 17 emotion items for which a Simultaneous Component Analysis indicated cross-culturally equivalence (see Online Supplementay Materials for the full list of emotions and De Leersnyder et al., 2011 for the full results of the SCA) and were transformed into Fischer z-scores. Participants' two z-scores were aggregated into one index of emotional fit with the Turkish average patterns.

Personal Factors of Cultural Engagement. Similar to Study 1, we operationalised Turkish Belgians' exposure to the heritage culture as the Number of Years and Proportion of Life spent in the heritage culture. Social Contact with Heritage Culture Members was measured 
RUNNING HEAD: EMOTIONAL FIT WITH THE HERITAGE CULTURE

through an eight item scale that asked participants whether they use to speak only Turkish (1), only Dutch (3) or both languages (2) when interacting with their partner, siblings, co-workers, neighbours, friends, etc. (De Leersnyder et al., 2011); Cronbach's $\alpha=.76$ ). We re-coded the scale such that higher scores indicate more Turkish (instead of Dutch) language use when having social contact $(M=2.00, S D=0.54)$. Since majority Belgians do not have any knowledge of Turkish, this scale is an indirect measure of the degree to which immigrants' social contacts are with heritage culture members. As an extra check, we directly asked minorities their agreement with the statement "I have a lot of Turkish friends" $(1=$ totally disagree $-7=$ totally agree $M=6.09 S D=1.44)$. We could not combine their answers with the indirect social contact scale because of the different scales.

As in Study 1, acculturation attitudes were measured by 8 items of the VIA (Ryder et al., 2000) that constituted two scales: one referring to Maintaining Values and Traditions (four items, $\alpha=.73 ; M=5.59, S D=1.17)$, the other referring to Maintaining Social Contacts with Heritage Culture Members (four items, $\alpha=.73 ; M=5.68, S D=1.17$ ). The two scales correlated substantially $\left(r_{(140)}=.68, p \leq .001\right)$, but nevertheless formed 2 factors in the PCA. ${ }^{3}$

Situational factor of Cultural Engagement: The situational factor was operationalized in the exact same way as in Study 1, namely by looking at whether the self-reported situations had taken place at home/with family versus at work/school (as defined by the prompt).

Procedure. Before each study, participants received, read, and signed an informed consent. The Belgian and Turkish Belgian community samples were recruited through centres for adult education and though flyers being distributed in (mainly) Turkish neighbourhoods in the city of Gent. The Turkish majority sample was recruited at the Educational Studies

3 Although one item did not load on the expected factor (Maintaining Values and Traditions), Cronbach's alpha got worse (instead of improved) when removing this item from the scale. Therefore, and in keeping with both Study 1 and the 2011 paper, we retained this item. 
Department of the Doküz Eylül University in Izmir, Turkey. Students volunteered in class time or during breaks.

\section{Results.}

Analytic strategy. We employed an analytic strategy that resembles the one used in Study 1. To assess group differences (H1), we conducted an ANOVA that tested differences in Turkish emotional fit between the different groups in our sample. To assess which personal factors were associated with heritage culture emotional fit, we again conducted a series of carefully planned regression analyses in which minorities' emotional fit with the Turkish patterns was predicted by their exposure to the Turkish context (Regression 1 and 2, testing H2 vs. H2A), by their general level of social contact with Turks (regression 3 testing H3) versus only by the number of heritage culture friends (regression 3 bis testing $\mathrm{H} 3 \mathrm{~A}$ ), and by their attitudes towards maintain Turkish Values and traditions and Turkish Social Contacts (Regression 4, testing H4). Again, these regressions consisted of several blocks with Blocks 1 and 2 including our control variables - i.e., the between-subject variables Valence and Relationship Context (Block 1) and participants' Educational Attainment (Block 2) - Block 3 each time including one predictor of interest and Blocks 4 to 6 testing all two-way and 3-way interactions.

To test $\mathrm{H} 5$ and thus to assess the influence of the situational factor on heritage culture emotional fit, we relied on Turkish Belgians' fit scores with both the average Turkish patterns and those with the average Belgian patterns established in previous work (De Leersnyder et al., 2011). Differently than in Study 1, the (optimised) design of Study 2 allowed us to conduct a Repeated Measures ANOVA that featured immigrants' emotional fit with the Turkish and the Belgian average patterns as dependent variables, and the Context of the prompt (home/ family vs. work/school) as predictor. In this analysis, we could also control for the (expectedly) strong 
RUNNING HEAD: EMOTIONAL FIT WITH THE HERITAGE CULTURE

valence effects and further explore whether the effects of situational engagement on emotional fit would differ across first and second generation minorities.

Personal factors: Which aspects of heritage engagement predict Turkish Belgians' heritage emotional fit? At the group level, we had hypothesized that the Turkish majority group would have higher fit to the average Turkish emotional patterns than the Turkish Belgian and Belgian groups (H1). Consistent with this hypothesis, an ANOVA yielded group differences in emotional fit $\left(F_{(3,449)}=4.099 ; p=.007, \eta^{2}=.027\right)$, showing that Turks in Turkey were significantly more concordant to the Turkish average patterns $(M=.80 ; S D=.46)$ than both Belgians $\left(M=.62 ; S D=.51 ; M_{\text {diff }}=.175 ; p=.008,95 \%\right.$ CI: $\left.[.047, .303]\right)$ and Turkish second generation immigrants $\left(M=.62 ; S D=.54 ; M_{\text {diff }}=.175 ; p=.005,95 \%\right.$ CI: $\left.[.052, .298]\right)$. The fit levels of Turkish first generation immigrants $(M=.70 ; S D=.53)$ were neither significantly lower than those of Turkish majorities $\left(M_{\text {diff }}=.104 ; p=.152,95 \%\right.$ CI: [-.038, .246]) nor significantly higher than those of second generation minorities and Belgian majorities (see Figure 1, right panel).

The regressions testing which personal factors of heritage culture engagement predict heritage culture fit, again pointed to a main effect of Valence (step $1 R^{2}$ change $=.53, p \leq .001$; $B$ ranging from -.755 to -.728, $p \leq .001$; see Table 1, panel B, Regressions $1-4$ ), indicating that emotional fit was higher in positive than in negative situations. As in Study 1, neither the other control variables (Context and Educational Attainment), nor any two-way or three-way interaction were significant; hence, we don't report on these results here (full details can be obtained from the first author).

Regressions 1 and 2 respectively revealed that neither the number of years spent in Turkey nor the proportion of life spent in Turkey predicted minorities' emotional fit with the Turkish patterns (for the full results, see Table 1, panel B), which supports the alternative H2A rather than $\mathrm{H} 2$. 
RUNNING HEAD: EMOTIONAL FIT WITH THE HERITAGE CULTURE

Regression 3 that predicted Turkish Belgians' heritage emotional fit from their daily social contacts with other Turkish (minority) people, found a trending effect of general social contact with Turks (step $3 R^{2}$ change $=.008, p=.139 ; B=.091, p=.139,95 \%$ CI: [-.030, .212]; see Table 1, panel B). To further explore this finding and test H3A that posited that heritage emotional fit is only a function of having heritage culture friends, we conducted an additional series of eight regression analyses in which we separately entered each individual item of the social contact scale as the predictor of interest. Supporting H3A, only Regression 3bis that included the item referring to friends yielded significant results (see Table 1, panel B): Speaking Turkish more with friends - as an indirect index of having more Turkish [minority] than Belgian majority friends - was positively associated with Turkish emotional fit (step $3 R^{2}$ change $=.029, p=.005 ; B=.116, p=.005,95 \%$ CI: $[.036, .195]$; see OSM Table 2A for the non-significant results on the other social contact items). This effect was still significant after applying Bonferroni corrections for multiple comparisons $(\alpha=.05 / 8=0.006)$. Moreover, it was corroborated by Regression 3cis that included minorities' explicitly stated number of Turkish friends as predictor of interest: Again, the more heritage culture friends, the higher minorities' heritage culture fit (step $3 R^{2}$ change $=.020, p=.016 ; B=.055, p=.016,95 \%$ CI: $[.011, .100]$; see Table 1).

Finally, we tested the associations between minorities' acculturation attitudes towards the Turkish culture and their emotional fit with the Turkish patterns (H4). Mirroring the results of Study 1, minorities' wish to maintain Turkish values and traditions was unrelated to emotional fit, but their wish to maintain social contacts with Turks' was marginally significantly associated, be it for home/family situations only (see Table 1, panel B, Regression 4; step $4 R^{2}$ change $=.028, p=.082$ ). Again, we conducted a post-hoc regression analysis to disentangle this effect of desiring social contact with heritage members from having actual contact with heritage members. Just like in Study 1, however, the effect of Attitudes towards Maintaining 
RUNNING HEAD: EMOTIONAL FIT WITH THE HERITAGE CULTURE

Social Contact with Heritage Members disappeared once we included the variables referring to actual contacts with heritage members. ${ }^{4}$ When all three contact-related items were included (step $3 R^{2}$ change $=.048, p=.004$ ), only Turkish Belgians' use of the Turkish language with friends significantly predicted their Turkish emotional fit $(B=.102, p=.013,95 \%$ CI: $[.022$, .182]; see Table 1, panel B). Turkish Belgians' fit to the typically Turkish emotional patterns is thus only associated with the extent to which they engage in actual heritage culture friendships.

Situational factor: Does interacting in Turkish cultural settings afford Turkish Belgians to fit the Turkish emotional patterns better? To test whether the situational factor Context shaped Turkish Belgians' emotional fit with their heritage culture (H5), we compared their fit with the typical Turkish versus typical Belgian emotional patterns in home/family versus work/school contexts. A Repeated Measures ANOVA with emotional fit scores as within-subjects variables and Valence, Context and Generation as between-subjects variables, provided initial support for H5. Confirming the findings reported above, this analysis yielded i) a significant within-subjects effect of Generation on Emotional Fit (Pillai's Trace $=.069$ $\left.F_{(1,130}=9.665, p=.002, \eta^{2}=.069\right)$ such that first generation minorities had a higher fit with the Turkish $(M=68, S E=.049)$ than the Belgian patterns $(M=.62, S E=.046 ;$ Mean_diff $=-.055$, $S E=.024, p=.023$ ), whereas the opposite was true for second generation minorities (Belgian fit: $M=.65, S E=.039$; Turkish fit: $M=.61, S E=.042 ;$ Mean_diff $=-.042, S E=.020, p=.038$ ), and ii) a significant between-subjects effect of Valence $\left(F_{(1,130}=159.89, p \leq .001\right)$. No other within-subject effects were significant, implying that the hypothesized three way interaction of Emotional Fit*Context*Generation also did not reach significance (Pillai's Trace $=.003 F_{(1,130}$

${ }^{4}$ Minorities' attitudes toward social contact with Turks were highly correlated with their explicit statement of having Turkish friends $(r=.435, p \leq .001)$, but uncorrelated with the more implicit measure of speaking Turkish among friends $(r=.061, p=.481)$; the latter two scales were moderately associated $(r=.171, p$ $=.047)$. 
$\left.=.440, p=.508, \eta^{2}=.003\right)$. However, as expected, the pattern of pairwise comparisons was very consistent with the trends observed in Study 1. Turkish first generation minorities were more concordant to Turkish $(M=.67, S E=.071)$ than to Belgian $(M=.61, S E=.066)$ emotional patterns in home/family contexts (Mean_diff $=.063, S E_{\text {mean diff }}=.034, p=.070$, one-tailed $p=$ $.035 ; 95 \%$ CI: $[-.005, .130])$, but did not differentiate between the patterns in work/school contexts. In contrast, second generation minorities were more concordant to Belgian $(M=.68$, $S E=.054)$ than to Turkish $(M=.60, S E=.058)$ patterns in work/school contexts $($ Mean_diff $=$ $.071, S E_{\text {mean diff }}=.028, p=.013$, one-tailed $\left.p=0.007 ; 95 \% \mathrm{CI}:[.015, .126]\right)$, but did not differentiate between Belgian and Turkish patterns at home (see Figure 2, right panel). Taken together, this set of results provides further tentative support for the idea that minorities switch cultural frames in the domain of emotions, but also suggests that the specific condition under which frame-switching occurs, may differ across first and second generation minorities.

\section{General Discussion}

The current research documents which personal and situational factors afford immigrant minorities to maintain their heritage culture's emotional patterns. It suggests that when immigrant minorities come to fit the emotional patterns typical of the new mainstream culture, they do not necessarily 'lose' their emotional concordance to their heritage culture. Rather, minorities may maintain (and perhaps even cultivate) their heritage emotional patterns through maintaining friendships with heritage culture members (personal factor) and interacting in situations that prompt and afford heritage cultural meanings and practices (situational factor). Specifically, our studies on Korean Americans and Turkish Belgians showed that minorities' emotional fit with the heritage culture was i) positively associated with their number of Korean and Turkish friends and ii) higher when interacting at home versus at school/work (although the latter was most outspoken for first generation minorities). Thus, the current studies consistently suggest that minorities' heritage culture emotional patterns are maintained (and 
perhaps even cultivated) through interacting with heritage culture friends and are most prominent (and thus activated) when it is most relevant: In contacts with other heritage members.

Before discussing these findings in detail, we will take a closer look at two other results that were not at the core of our research, but that are nevertheless important. Firstly, and replicating other studies on emotional fit with culture (De Leersnyder et al., 2011; Jasini et al., 2019), we found that fit in positive situations is significantly higher than fit in negative situations, and that this result holds true for both majority and minority members. As speculated before (De Leersnyder et al., 2011), this may be due to the fact that negative emotional situations are more complex than positive ones - something that is also reflected by the higher sum of variances of all emotion terms in the negative (73.6 in Study 1 and 79.7 in Study 2) than in the positive situations (51.6 in Study 1 and 49.2 in Study 2). Importantly, however, we found no differences with regard to the associations between the various personal factors and emotional fit in positive versus negative situations: None of the interaction effects between Valence and our predictors of interest were significant. The only exception to this was that Korean Americans' friendships with Koreans only contributed to their fit with the typical Korean patterns for negative emotional situations, and not to their fit in positive situations. One potential explanation for this is that whereas positive situations are discussed with many others, negative situations, and especially negative engaging ones (that center around shame) are mainly discussed with close friends (Rimé, Mesquita, Phillipot \& Boca, 1991). Therefore, having Korean friends may be especially important for Korean Americans to maintain fit with the typical Korean patterns in negative situations.

A second finding that was not at the core of our hypotheses, but that can shed important light on the nature of emotional fit with culture, is that immigrant minorities seemed to fit their heritage culture patterns about equally well as they fit their new majority culture patterns (De 
Leersnyder et al., 2011), while majority members only fitted to their own and not the other culture's patterns. To underpin this observation with statistics, we conducted, for each study, a post-hoc repeated measures ANOVA in which we predicted all participants' level of emotional fit with both the new mainstream (i.c., European American, Belgian) and the heritage (i.c., Korean, Turkish) typical patterns of emotion from their group membership. We found that all majority groups (Koreans, European Americans, Turks, Belgians) were significantly more concordant to their own than to another culture's emotional patterns, but that immigrant minorities' fitted both patterns about equally well (see Online Supplementary Materials for a full report). This suggests that for immigrant minorities the new mainstream and heritage culture's emotional patterns tend to co-exist.

\section{Predicting maintenance of heritage culture emotional patterns}

The current research started from the observation that most immigrant minorities engage in heritage cultural contexts on a daily basis, and clarified which aspects of heritage engagement are associated with minorities maintaining their heritage emotional patterns. Whether immigrant minorities have heritage culture friends was the only personal factor that predicted emotional fit with the heritage culture across both studies. Neither length of time spent in the country of origin nor age at immigration predicted the emotional fit with the heritage culture findings that can be understood from the fact that our minority participants (like so many other minorities) live in ethnic enclaves that expose them to (a form of) the heritage culture. Also, participants' general level of social contact with heritage members did not predict heritage emotional fit, perhaps because there is less meaningful variation in minorities' number of heritage culture family members and colleagues. The fact that it was a function of one's contact with heritage culture friends further supports the idea that friendships may play a particularly important role in the (re)negotiation of emotional meanings while sharing emotional events. 
RUNNING HEAD: EMOTIONAL FIT WITH THE HERITAGE CULTURE

Future research should further investigate these explanations by, for instance, explicitly testing to what extent i) these different indicators of heritage culture engagement are associated with the endorsement of heritage culture meanings and practices and ii) minorities actually share their emotional experiences much more with heritage culture friends than with family members, co-workers and neighbours. Relatedly, future research could further examine why having Korean friends was a predictor of Korean Americans' emotional fit to the Korean average emotional patterns for negative situations only (Study 1; see above).

Despite these remaining questions, the current research documents which aspects of minorities' engagement in the heritage culture are associated with their maintenance of heritage culture patterns and which aspects are not. In this way it contributes to a more complete understanding of emotional acculturation. The fact that the predictors of mainstream and heritage cultural fit do not mirror one another perfectly may fuel further research, and shed light on the group-level findings discussed earlier. If anything, the results show that when immigrant minorities engage in a new cultural context, they are not 'doomed to lose' their heritage culture emotional patterns, especially not when they engage in friendships with heritage culture members.

\section{Towards a situated and heterogeneous approach of acculturation}

Our findings inform acculturation psychology in several ways. Firstly, studies on acculturative changes in emotional patterns complement traditional acculturation research that has focused on minorities' attitudes and cultural identities, which are deliberate, conscious, articulate, and reflective positions towards the mainstream and heritage cultures (e.g., (Berry, 1997; Phinney, 1990; Sam \& Berry, 2010). It calls for a 'cultural psychological' approach to acculturation (see De Leersnyder, 2014; Mesquita, De Leersnyder, \& Jasini, 2019) in which all aspects of people's psychological functioning, such as their self-esteem (Heine \& Lehman, 
RUNNING HEAD: EMOTIONAL FIT WITH THE HERITAGE CULTURE

2004), self-construal (De Leersnyder, 2009), personality (Güngör et al., 2013) and emotional lives may be subject acculturation.

Secondly, the finding that emotional fit to the heritage culture was dissociated from minorities' explicit attitudes towards maintaining the heritage culture commends interpreting emotional concordance as a more implicit reflection of acculturation. Moreover, it calls for a novel view on acculturation in which different aspects of minorities' psychological functioning may acculturate at different paces or even in different directions. As found here and elsewhere (i.c. De Leersnyder et al., 2011; Jasini, et al., 2019), minorities' explicitly held (attitudes, identities) and implicitly embodied (emotions) cultural affiliations could be more heterogeneous than previously assumed.

\section{Cultural frame switching in emotions}

In addition to providing insight in (emotional) acculturation, our findings also speak to cultural frame switching (e.g., Hong et al., 2000). By showing that minorities' emotional patterns were more concordant with heritage culture patterns in situations that took place at home/with family, whereas they were more concordant with majority patterns in work/school situations, the current research provides additional evidence for cultural frame switching in the domain of emotions. These findings were moderated by minorities' generational status, though, with first generation minorities showing more distinct patterns of emotions at home/with family and second generation minorities showing more distinct patterns at school/work. This may be so, because first generation minorities - who grew up in the heritage country - may have a more clear picture of how emotional responses should look like in (heritage culture) family situations than in (majority) work/school situations, while the opposite may be true for second generation minorities who grew up in the new mainstream context - a speculation that needs to be addressed in future research. 
RUNNING HEAD: EMOTIONAL FIT WITH THE HERITAGE CULTURE

Nevertheless, the current findings go beyond the only other study on emotional frame switching (Perunovic et al., 2007) in several ways. Firstly, they document cultural frame switching in the patterning of emotions rather than in associations between average levels of positive and negative moods. Secondly, and most importantly, they are based on actually measured instead of inferred fit between minorities' emotions and those that are typical for the heritage and mainstream cultures. Of course, future research should address the exact differences between heritage and new mainstream emotional patterns as well as examine which contextual cues activate each of these culture's emotional patterns.

\section{Emotions}

Finally, the current studies also speak to our understanding of emotions per se. The finding that minorities continue to fit emotionally with their heritage culture upon engaging in heritage culture friendships supports the idea that people's - ongoing and multiple - cultural engagements shape their experiences to be in line with them (e.g., Mesquita, 2003; Mesquita et al., 2017). Furthermore, the additional evidence for minorities' frame switching between heritage and new mainstream patterns of emotion, can be taken as support for the idea that people construe their emotional experiences dynamically and thus 'in the moment' to be in line with the prevailing cultural context (e.g., Boiger \& Mesquita, 2012).

\section{Limitations}

The current research has some limitations. First, the sample size of Study 1 was rather small, which may have weakened the power of our analyses. Yet, as the results of Study 1 were replicated in Study 2, we have confidence that the findings can be interpreted, especially given the fact that the two case studies were maximally different yet theoretical replications from one another. Second, we calculated emotional concordance for home/family and work/school contexts as we assumed that the heritage culture is salient in home/family contexts and the majority culture is pertinent in work/school contexts. In reality, these contexts may be less 
culturally homogenous, due to people from diverse ethnic backgrounds being present at the same time, switching between different languages of interaction, and the simultaneous presence of cultural symbols that refer to the new and the heritage context. If anything, the dynamics of emotional acculturation may thus still be more complex than we outlined here.

\section{Conclusion}

In sum, the current research documented the personal and situational factors that afford immigrant minorities to maintain emotional patterns that are typical for their heritage cultural context. It suggests that minorities do not lose existing heritage emotional patterns when they acquire new mainstream emotional patterns, but can continue to maintain these patterns while interacting with heritage culture friends. In addition, it suggests that minorities may switch between heritage and new mainstream emotional patterns depending on the context of interaction: When interacting in heritage cultural settings (at home) they are more concordant to typical heritage than to typical majority emotional patterns, while the opposite is true when interacting in majority cultural settings (at work/school). As such, the current research shows that minorities' emotional patterns are not only cultivated, but also activated by their interactions in different socio-cultural contexts. 
RUNNING HEAD: EMOTIONAL FIT WITH THE HERITAGE CULTURE

\section{References}

Alba, R. (2005). Bright vs. blurred boundaries: Second-generation assimilation and exclusion in France, Germany, and the United States. Ethnic and Racial Studies (Vol. 28). http://doi.org/10.1080/0141987042000280003

Berry, J. W. (1997). Immigration, acculturation, and adaptation. Applied Psychology: An International Review, 46(1), 5-34. http://doi.org/10.1111/j.1464-0597.1997.tb01087.x

Boiger, M., Güngör, D., Karasawa, M., \& Mesquita, B. (2014). Defending honour, keeping face: Interpersonal affordances of anger and shame in Turkey and Japan. Cognition \& Emotion, 28(7), 1255-1269. http://doi.org/10.1080/02699931.2014.881324

Boiger, M., \& Mesquita, B. (2012). The construction of emotion in interactions, relationships, and cultures. Emotion Review, 4(3), 221-229. http://doi.org/10.1177/1754073912439765

Boiger, M., Mesquita, B., Uchida, Y., \& Barrett, L. F. (2013). Condoned or condemned: The situational affordance of anger and shame in the United States and Japan. Personality and Social Psychology Bulletin, 39(4), 540-553. http://doi.org/10.1177/0146167213478201

Briley, D. a., Morris, M. W., \& Simonson, I. (2005). Cultural chameleons: Biculturals, conformity motives, and decision making. Journal of Consumer Psychology, 15(4), 351362. http://doi.org/10.1207/s15327663jcp1504_9

Consedine, N. S., Chentsova-Dutton, Y. E., \& Krivoshekova, Y. S. (2014). Emotional acculturation predicts better somatic health: Experiental and expressive acculturation among immigrant women from four ethnic groups. Journal of Social and Clinical Psychology, 33(10), 867-889. https://doi.org/10.1521/jscp.2014.33.10.867

De Leersnyder, J. (2009). Turkish Belgians' Acculturation of Self-construal. Leuven. 
RUNNING HEAD: EMOTIONAL FIT WITH THE HERITAGE CULTURE

De Leersnyder, J. (2014). Emotional Acculturation. University of Leuven.

De Leersnyder, J. (2017). Emotional Acculturation: A first Review. Current Opinion in Psychology, 17, 67-73. http://doi.org/10.1016/j.copsyc.2017.06.007

De Leersnyder, J., Kim, H., \& Mesquita, B. (2015). Feeling right is feeling good: Psychological well-being and emotional fit with culture in autonomy- versus relatedness-promoting situations. Frontiers in Psychology, 6, 1-12. http://doi.org/10.3389/fpsyg.2015.00630

De Leersnyder, J., Koval, P., Kuppens, P., \& Mesquita, B. (2018). Emotions and concerns: Situational evidence for their systematic co-occurrence. Emotion, 18(4), 597-614. http://doi: 10.1037/emo0000314.

De Leersnyder, J., Mesquita, B., Kim, H., Eom, K., \& Choi, H. (2014). Emotional fit with culture: A predictor of individual differences in relational well-being. Emotion, 14(2), 241-245. http://doi.org/10.1037/a0035296

De Leersnyder, J., Mesquita, B., \& Kim, H. S. (2011). Where do my emotions belong? A study of immigrants' emotional acculturation. Personality \& Social Psychology Bulletin, 37(4), 451-63. http://doi.org/10.1177/0146167211399103

De Roover, K., Ceulemans, E., Timmerman, M. E., Vansteelandt, K., Stouten, J., \& Onghena, P. (2012). Clusterwise simultaneous component analysis for analyzing structural differences in multivariate multiblock data. Psychological Methods, 17, 100-119.

FOD Werkgelegenheid, A. en S. O. (2009). Immigratie in België: aantallen, stromen en arbeidsmarkt (De). [Immigration in Belgium: numbers, flows and labor market].

Güngör, D., Bornstein, M. H., De Leersnyder, J., Cote, L., Ceulemans, E., \& Mesquita, B. (2013). Acculturation of personality: A three-culture study of Japanese, Japanese 
RUNNING HEAD: EMOTIONAL FIT WITH THE HERITAGE CULTURE

Americans, and European Americans. Journal of Cross-Cultural Psychology. http://doi.org/10.1177/0022022112470749

Heine, S. J., \& Lehman, D. R. (2004). Move the body, change the self: Acculturative effects on the self-concept. In M. Schaller \& C. Crandall (Eds.), Psychological Foundations of Culture (pp. 305-331). Mahwah, NJ: Erlbaum.

Hong, Y. Y., Morris, M. W., Chiu, C. Y., \& Benet-Martínez, V. (2000). Multicultural minds: A dynamic constructivist approach to culture and cognition. The American Psychologist, 55(7), 709-720. http://doi.org/10.1037/0003-066X.55.7.709

Jasini, A., De Leersnyder, J., Kende, J., Gagliolo, M., Phalet, K., \& Mesquita, B. (submitted). Show me your friends, I'll tell you your emotions: Emotional acculturation of immigrant minority youth in cross-cultural friendship networks. Manuscript submitted for publication.

Jasini, A., De Leersnyder, J., Phalet, K., \& Mesquita, B. (2019). Tuning in emotionally: Associations of cultural exposure with distal and proximal emotional fit in acculturating youth. European Journal of Social Psychology. $49 \quad$ (2), 352-365. https://doi.org/10.1002/ejsp.2516

Kitayama, S., \& Imada, T. (2010). Implicit independence and interdependence: A cultural task analysis. In B. Mesquita, L. F. Barrett, \& E. R. Smith (Eds.), The mind in context (pp. 174200). New York, NY: Guilford.

Kitayama, S., Mesquita, B., \& Karasawa, M. (2006). Cultural affordances and emotional experience: Socially engaging and disengaging emotions in Japan and the United States. Journal of Personality and Social Psychology, 91(5), 890-903. http://doi.org/10.1037/0022-3514.91.5.890 
RUNNING HEAD: EMOTIONAL FIT WITH THE HERITAGE CULTURE

Kosic, A., \& Phalet, K. (2006). Ethnic categorization of immigrants: The role of prejudice, perceived acculturation strategies and group size. International Journal of Intercultural Relations, 30(6), 769-782. http://doi.org/10.1016/j.ijintrel.2006.06.003

LaFromboise, T., Coleman, H., \& Gerton, J. (1993). Psychological impact of biculturalism: Evidence and theory. Psychological Bulletin, 114, 395-412.

Markus, H. R., \& Kitayama, S. (1991). Culture and self: Implications for cognition, emotion, and motivation. Psychological Review 98, 224-253. https://doi.org/10.1037/0033295X.98.2.224.

Mesquita, B. (2001). Emotions in Collectivist and Individualist Contexts. Journal of Personality and Social Psychology, 80(1), 68-74. DOI: 10.1037//0022-3514.80.1.68

Mesquita, B. (2003). Emotions as dynamic cultural phenomena. In R. J. Davidson, K. R. Scherer, \& H. H. Goldsmith (Eds.), Handbook of affective sciences (pp. 871-890). Oxford: Oxford Univeristy Press.

Mesquita, B., Boiger, M., \& De Leersnyder, J. (2016). The cultural construction of emotions. Current Opinion in Psychology, 8, 31-36. http://doi.org/10.1016/j.copsyc.2015.09.015

Mesquita, B., Boiger, M., \& De Leersnyder, J. (2017). Doing Emotions: The Role of Culture in Everyday Emotions. European Review of Social Psychology, 28 (1), 95-133. https://doi.org/10.1080/10463283.2017.1329107.

Mesquita, B., De Leersnyder, J., \& Jasini, A. (2019). The Cultural Pscyhology of Acculturation. In S. Kitayama \& D. Cohen (Eds.), Handbook of cultural Psychology (2 nd). New York, NY: Guilford Press.

Perunovic, W. Q. E., Heller, D., \& Rafaeli, E. (2007). Within-person changes in the structure 
RUNNING HEAD: EMOTIONAL FIT WITH THE HERITAGE CULTURE

of emotion: The role of cultural identification and language. Psychological Science, 18(7), 607-13. http://doi.org/10.1111/j.1467-9280.2007.01947.x

Phinney, J. S. (1990). Ethnic identity in adolescents and adults: Review of research. Psychological Bulletin, 10(3), 499-514. DOI: 10.1037/0033-2909.108.3.499.

Ramírez-Esparza, N., Gosling, S. D., Benet-Martínez, V., Potter, J. P., \& Pennebaker, J. W. (2006). Do bilinguals have two personalities? A special case of cultural frame switching. Journal of Research in Personality, 40(2), 99-120. http://doi.org/10.1016/j.jrp.2004.09.001

Rimé, B., Mesquita, B., Phillipot, P., \& Boca, S. (1991). Beyond the emotional event: Six studies on the social sharing of emotion. Cognition and Emotion, 5 (5/6), 435-465. https://doi.org/10.1080/02699939108411052.

Rothbaum, F. M., Pott, M., Azuma, H., Miyake, K., \& Weisz, J. R. (2000). The development of close relationships in Japan and the United States: Paths of symbiotic harmony and generative tension. Child Development, 71(5), 1121-1142. DOI: 10.1111/14678624.00214.

Ryder, A. G., Alden, L. E., \& Paulhus, D. L. (2000). Is acculturation unidimensional or bidimensional? A head-to-head comparison in the prediction of personality, self-identity, and adjustment. Journal of Personality and Social Psychology, 79(1), 49-65. http://doi.org/10.1037//0022-3514.79.1.49

Sam, D. L., \& Berry, J. W. (2010). Acculturation: When individuals and groups of different cultural backgrounds meet. Perspectives on Psychological Science, 5(4), 472-481. http://doi.org/10.1177/1745691610373075

Schwartz, S. J., Unger, J. B., Zamboanga, B. L., \& Szapocznik, J. (2011). How selective is 
RUNNING HEAD: EMOTIONAL FIT WITH THE HERITAGE CULTURE

acculturation? Broadening our perspective. American Psychologist, 66(2), 155-157. http://doi.org/10.1037/a0022560

Snauwaert, B., Soenens, B., Vanbeselaere, N., \& Boen, F. (2003). When integration does not necessarily imply integration: Different conceptualizations of acculturation orientations lead to different classifications. Journal of Cross-Cultural Psychology, 34(2), 231-239. http://doi.org/10.1177/0022022102250250

Terrazas, A. (2009). Korean Immigrants in the United States. Retrieved from Migration Policy Institute website: http://www.migrationinformation.org/USfocus/display.cfm? ID=716.

Tsai, J. L., Knutson, B., \& Fung, H. H. (2006). Cultural variation in affect valuation. Journal of Personality and Social Psychology, 90(2), 288-307. http://doi.org/10.1037/00223514.90.2.288

Van Acker, K. (2012). Flanders' real and present threat. How representations of intergroup relations shape attitudes towards Muslim minorities. Unpublished doctoral dissertation, University of Leuven, Leuven, Belgium.

van den Broek, A., \& van Ingen, E. (2008). Sociale contacten in de vrije tijd [Social contacts in leisure time]. In A. van den Broeck \& S. Keuzenkamp (Eds.), Het dagelijks leven van allochtone stedelingen [The daily life of ethnic minority citizens] (pp. 101-124). Den Haag: Sociaal en Cultureel Planbureau.

Verkuyten, M., \& Pouliasi, K. (2002). Biculturalism among older children: Cultural frame switching, attributions, self-identification, and attitudes. Journal of Cross-Cultural Psychology, 33(6), 596-609. http://doi.org/10.1177/0022022102238271

Yoo, D., \& Chung, R. H. (2009). Religion and spirituality in Korean America. Urbana: University of Illinois Press. 


\begin{tabular}{|c|c|c|c|c|c|c|}
\hline & Regression 3bis & $\Delta \mathbf{R}^{2}$ & $\boldsymbol{\beta}^{\mathbf{a}}$ & Regression 3bis & $\Delta \mathbf{R}^{2}$ & $\boldsymbol{\beta}^{\mathbf{a}}$ \\
\hline Step 1 & & $.369 * *$ & & Step 1 & $.526 * * *$ & \\
\hline & Valence & & $-.584 * * *$ & Valence & & $-750 * * *$ \\
\hline & Engagement & & .086 & Context & & .017 \\
\hline Step 2 & & .000 & & Step 2 & .001 & \\
\hline
\end{tabular}

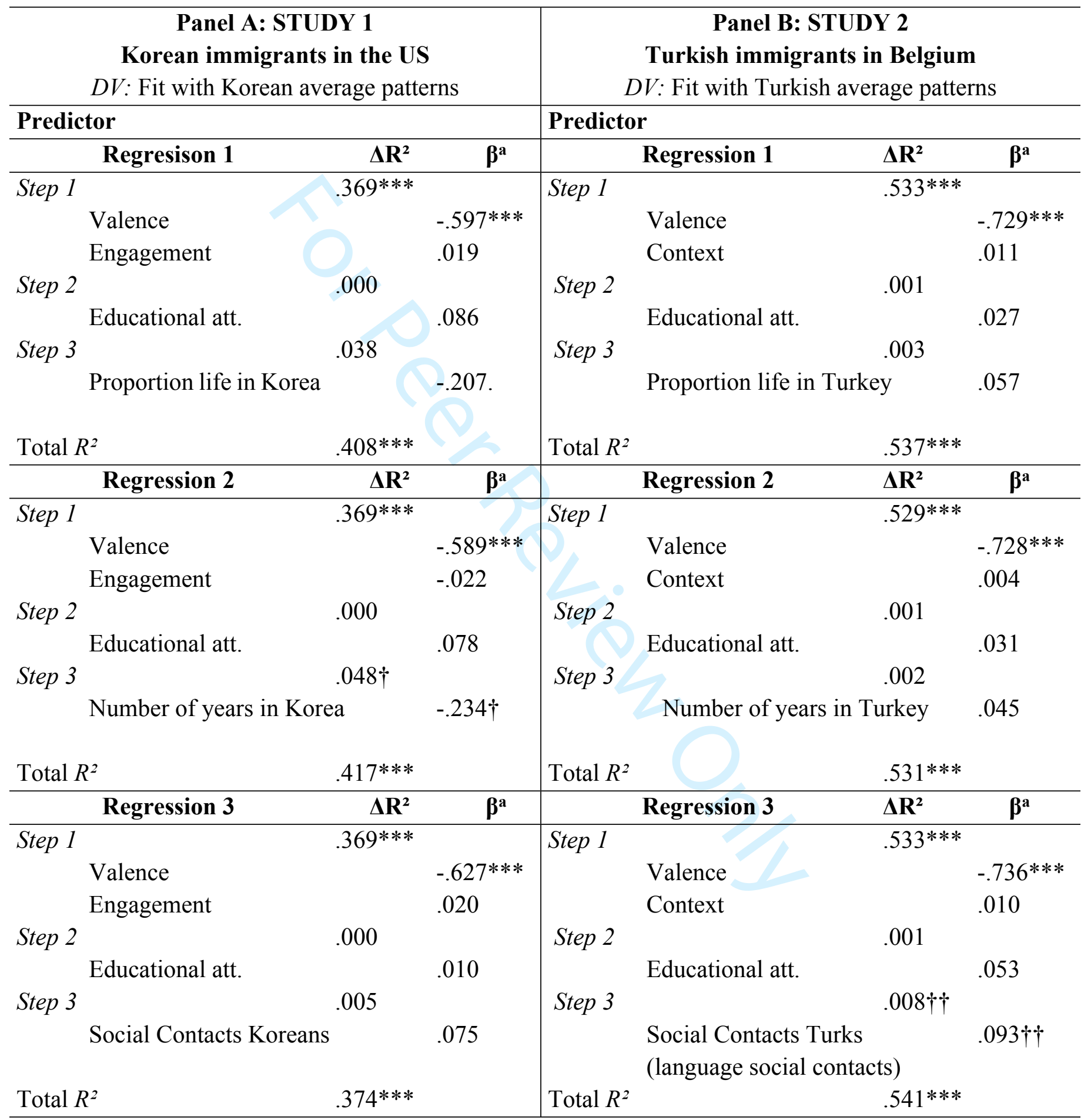

Table 1.

Hierarchical Multiple Regression Analyses Predicting Minorities' Emotional Fit with the Heritage Culture's Average Emotional Patterns. 
Educational att. .006

Step 3

Korean friends

Step 4 $.132 *$

Total $R^{2}$

Valence* Korean friends

$454^{*}$

Engagement*Korean friends

Educational att.

.064

Step 3

$.029 * *$

Turkish friends

$.176^{* *}$

(language with friends)

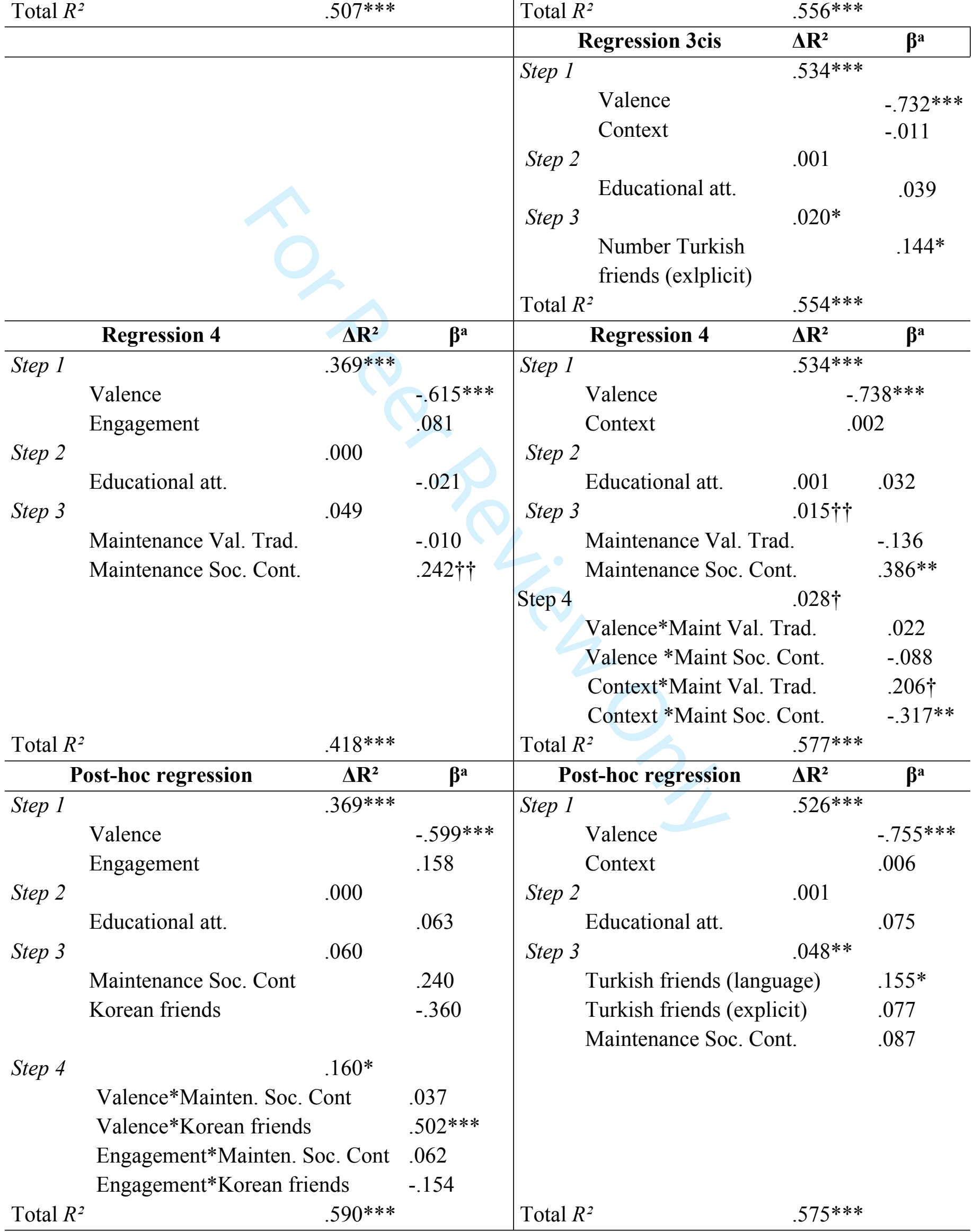


Note. ${ }^{\text {a }}$ The $\beta$ 's presented here are the ones from the final regression model, i.e. the latest step that significantly contributed to the explained variance. None of the three-way interactions (step 5) and the interactions between predictors of interest and Educational attainment (step 6) were significant. Therefore, the final models are either those of step 3 or step 4 .

Regression 1: predictor of interest is the proportion of life spent in the heritage culture; Regression 2: predictor of interest is the number of years spent in the heritage culture; Regression 3: predictor of interest is the amount of social contact with members from the host group; Regression 3_bis: predictor of interest is the extent to which one's friends are from the heritage culture; Regression 4: predictors of interest are minorities' attitudes towards the maintenance of values and traditions and attitudes towards social contact with people from the heritage cultural group. Post-hoc Regression: the predictors of interest are both the attitudinal and behavioral measures referring to having heritage culture friends. The between-brackets term (language) in study 2 refers to scales that tapped into one's Turkish versus Dutch language use as an indirect indictor of the ethnicity of one's social contacts.

$\dagger p \leq .150 ; \dagger p \leq .100 ; * p \leq .050 ; * * p \leq .010 ; * * * p \leq .001$ 


\section{Study 1: \\ Emotional Fit with Korean average patterns}

\section{Study 2: \\ Emotional Fit with Turkish \\ average patterns}

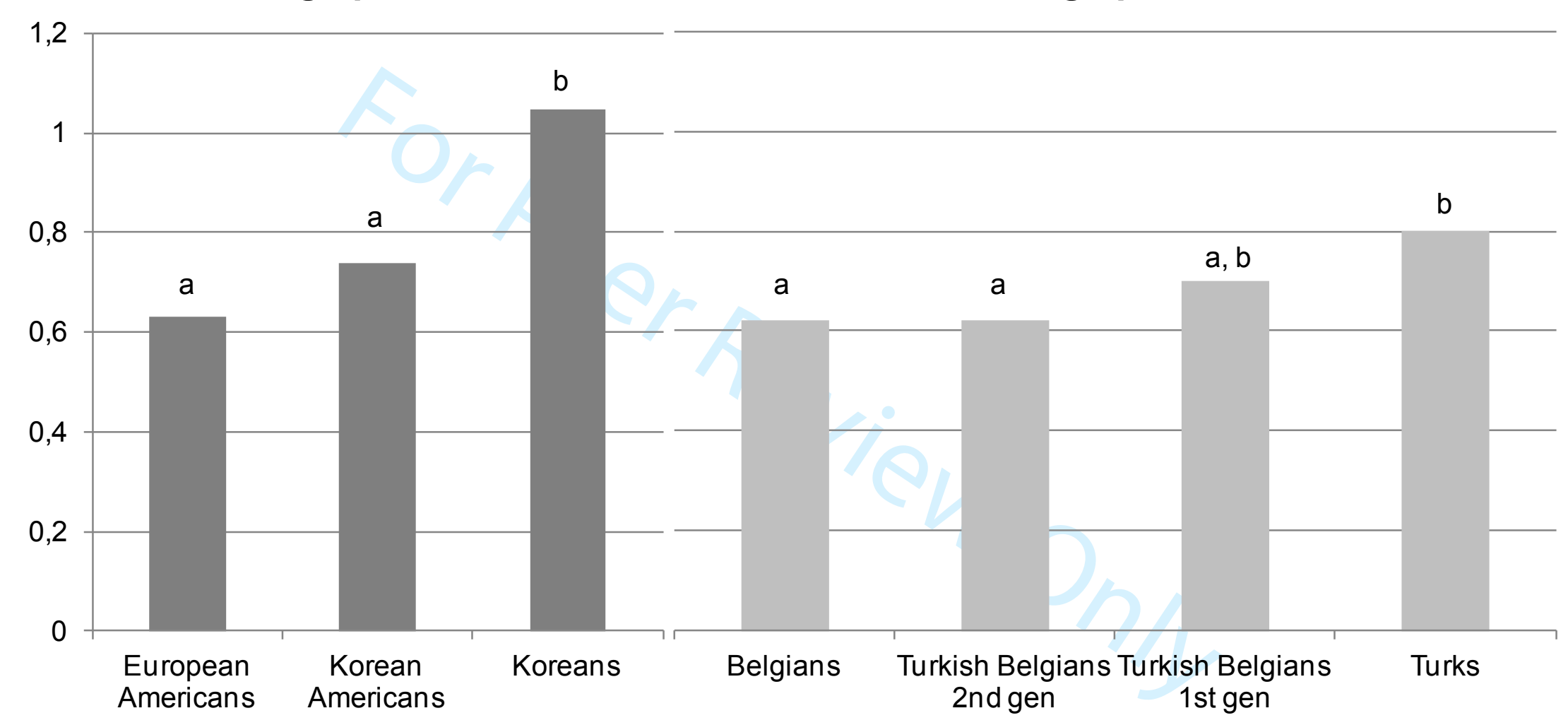

Figure 1. Mean levels of cultural groups' emotional concordance scores to the typical Korean and Turkish patterns of emotion. Within each study, groups with a similar letter did not differ significantly from one another whereas groups with a different letter were significantly different in their emotional fit scores. 


\section{Study 1}

Emotional Fit with European American average patterns

Emotional Fit with Korean average patterns
Study 2

Emotional Fit with Belgian average patterns

$\square$ Emotional Fit with Turkish average patterns

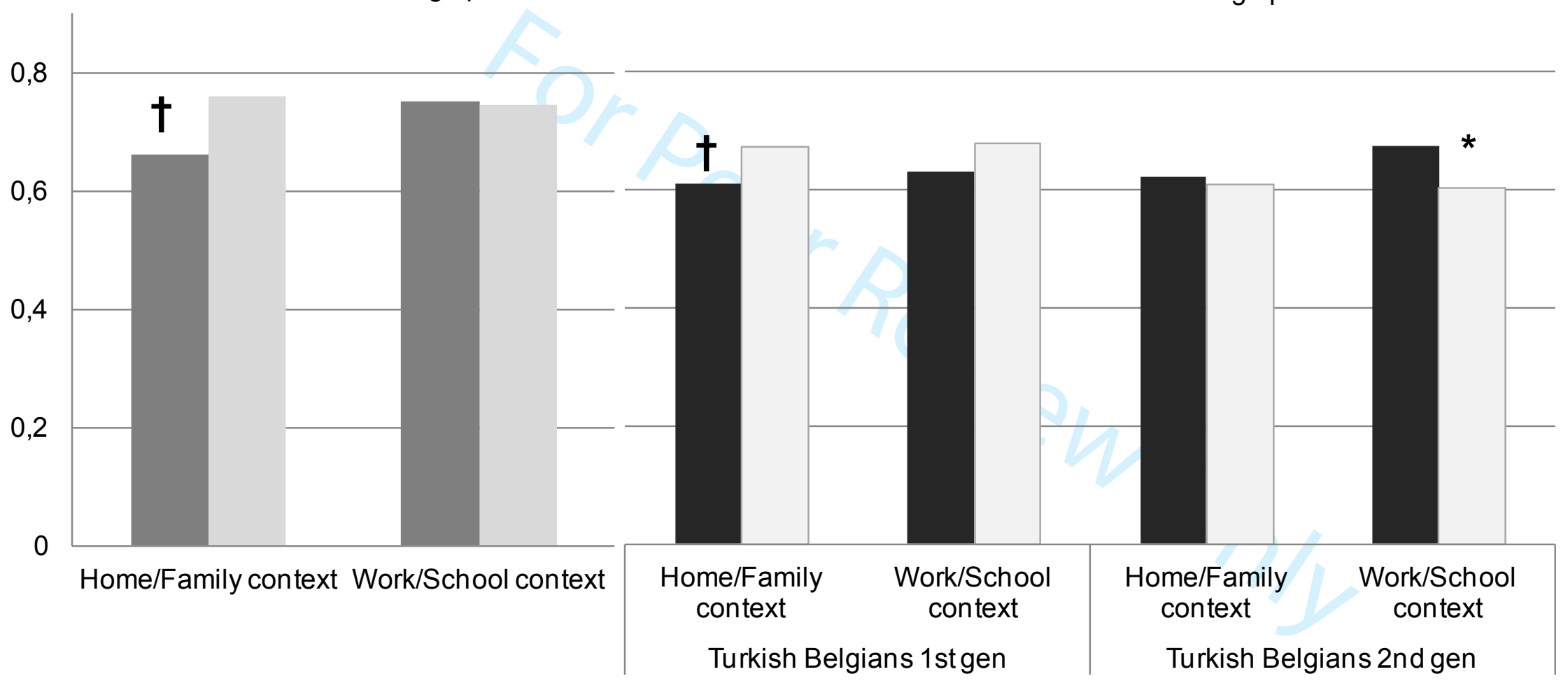

Figure 2. Mean levels of minorities' emotional concordance scores to the typical emotional patterns of both the heritage and mainstream cultural groups in home and work contexts. Significant differences between both emotional fit scores within a cultural group are indicated.

$\dagger p \leq .07 * p \leq .05$ 
ONLINE SUPPLEMENTARY MATERIALS: EMOTIONAL FIT WITH THE HERITAGE CULTURE

\author{
My Emotions Belong Here and There: \\ Extending the Phenomenon of Emotional Acculturation to Heritage Culture Fit. \\ Jozefien De Leersnyder ${ }^{1}$, Heejung Kim $^{2}$, \& Batja Mesquita ${ }^{1}$ \\ ${ }^{1}$ KU Leuven, ${ }^{2}$ University of California Santa Barbara
}

\title{
1. Additional Statistics Study 1.
}

\subsection{Detailed description of demographic differences between the samples Study 1 (p. 11)}

The Korean majority, Korean American and European American samples were comparable in terms of self-reported social class (measured on a scale from $1=$ lower class, till $5=$ upper class $;$ Mean_European American $=3.05 ; S D \_$European American $=1.0 ;$ Mean_Korean American $=$ 3.17; $S D \_$Korean American $=1.2 ;$ Mean_Korean $=2.88 ; S D \_$Korean $\left.=.76 ; F=1.594, p=.206\right)$, level of education (measured by a categorical variable representing $1=$ no or primary education; $2=$ high school; 3 = college; 4 = graduate, master, $\left.P h D ; \chi^{2}(6)=9.259, p=.160\right)$, and gender composition (European American $=40 \%$ females; Korean American $=46 \%$ females; Korean $=$ $59 \%$ females; $\left.\chi^{2}(2)=4.741, p=.093\right)$. However, they differed in terms of age $(F=16.739, p \leq$ $.001)$, with Koreans $\left(M_{\mathrm{age}}=27.9 ; S D_{\mathrm{age}}=4.3\right)$ being younger than both Korean Americans $\left(M_{\text {age }}\right.$ $=38.2 ; S D_{\mathrm{age}}=12.8 ;$ Mdiff $\left.=-10.317 ; t_{(50.96)}=-5.280, p \leq .001\right)$ and European Americans $\left(M_{\text {age }}\right.$ $=37.6 ; S D_{\mathrm{age}}=16.6 ;$ Mdiff $\left.=-9.762 ; t_{(43.95)}=-3.741, p=.001\right)$.

\subsection{Study 1: Testing the interaction between the situational factor and generational status}

on Korean American's emotional fit with both the typical Korean and European American patterns, page 19.

To test whether the situational effect on Korean American's emotional fit with the typical Korean and European American patterns differed by generational status, we conducted a repeated measures ANOVA in which participants' four different fit scores were the dependent variables (i.c. fit with Korean pattern at home, fit with European American pattern at home, fit with Korean pattern at work/school, fit with European American pattern at work/school) and 
generational status functioned as the independent variable. This analysis did not yield a main effect of generational status (Pillai's Trace $=.044, F_{(3,37)}=1.347, p=.642, \eta^{2}=.044$ ). However, the pairwise comparisons revealed that the pattern of emotional fit scores looked quite different for first than for second or later generation participants, with the only significant difference being that first generation minorities fitted the Korean patterns better than the European American patterns for situations that had taken place at home or with family members $\left(\right.$ Mean_diff $=.154, S E_{\text {mean diff }}=.06, p=.014 ; 95 \%$ CI: $[.033, .275]$.

\section{Additional Statistics Study 2.}

\subsection{Detailed description of demographic differences between the samples Study 2 (p. 18)}

Across the Turkish majority, Turkish Belgian and Belgian majority samples there was a significant difference in age: the Turkish majority students $(M=20.1, S D=1.47)$ were significantly younger than the first generation minorities $(M=34.1, S D=10.85$; Mean diff $=$ $\left.14.01, t_{(55.46)}=9.645, p \leq .001\right)$, the second generation minorities $(M=25.59, S D=6.63 ;$ Mean diff $\left.=5.53, t_{(86.85)}=7.623, p \leq .001\right)$ and the Belgian majority participants $\left(M=31.38, S D_{\mathrm{a}}=\right.$ 8.67; Mean diff $\left.=11.33, t_{(78.40)}=11.486, p \leq .001\right)$. Furthermore, the Turkish majority sample was characterized by a higher proportion of female participants ( $67 \%$ females) than the other three samples (around 50\%; $\chi^{2}=10.338, p=.016$ ). As could be expected based on our sampling strategy, there was a difference in the level of educational attainment between the community samples (Turkish Belgian first and second generation minority and Belgian majority members) on the one hand and the student sample on the other hand (Turkish majority; $\chi^{2}=81.640, p \leq$ $.001)$. Specifically, whereas $23 \%-35 \%$ of the participants from our community samples held a tertiary education degree, none of the Turkish students did, which is quite logical given that they were still studying. The three community samples did not differ from one another in terms the level of educational attainment $\left(\chi^{2}=3.598, p=.165\right)$. 
ONLINE SUPPLEMENTARY MATERIALS: EMOTIONAL FIT WITH THE HERITAGE CULTURE

\section{Additional Statistics Discussion}

\section{Post-hoc analysis on the absolute levels of emotional fit with two culture's typical patterns} of emotion in both monocultural majority members (own versus other culture patterns) and immigrant minority embers (new mainstream versus heritage culture patterns; $\mathbf{p}$. 29).

\subsection{Study 1}

We conducted a repeated-measures ANOVA in which participants' emotional fit with the Korean average pattern and with the European American average pattern functioned as the dependent variables and Culture served as the only predictor. This analysis yielded a strong interaction effect between Culture and the different Types of Emotional Fit (Pillai's Trace = $\left..346, F_{(2,163)}=43.147, p \leq .001, \eta^{2}=.346\right)$. Pairwise comparisons revealed that i) Korean Americans' fit with the Korean average emotional pattern $(M=.74, S E=.061)$ was not different from their fit with the European American average pattern $(M=.72, S E=.054$; Mean diff $=$ $\left..020, S E_{\text {mean diff }}=.036, p=.584\right)$; that ii) Koreans had significantly higher fit to the Korean average patterns $(M=1.05, S E=.046)$ than to the European American average patterns $(M=$ $.74, S E=.040 ;$ Mean diff $\left.=.308, S E_{\text {mean diff }}=.027, p \leq .001\right)$ and that iii) European Americans had significantly higher fit to the European American $(M=.71, S E=.056)$ than to the Korean average patterns $\left(M=.63, S E=.063 ;\right.$ Mean diff $\left.=.083, S E_{\text {mean diff }}=.037, p=.026\right)$.

In addition, there was a significant main effect of Type of Emotional Fit (concordance to Korean patterns was overall higher than concordance to European American patterns; Pillai's Trace $=.098, F_{(1,163)}=23.126, p \leq .001, \eta^{2}=.098$, which may be due to the larger sample of Koreans) and a main effect of Culture indicating that Korean majority members had overall a better fit to both average emotional patterns $\left(F_{(2,163)}=5.914, p=.003, \eta^{2}=.068\right)$, a finding that made us wonder whether the difference in design could have played a role here. 
ONLINE SUPPLEMENTARY MATERIALS: EMOTIONAL FIT WITH THE HERITAGE CULTURE

\subsection{Study 2}

Similar to Study 1, we conducted a repeated measures ANOVA included participants' emotional fit with the Belgian average pattern and with the Turkish average pattern as the dependent variables and Valence, Context and Culture as between-subject variables. It revealed a strong interaction effect between Culture and Type of Emotional Fit (Pillai's Trace $=.228$, $\left.F_{(3,433)}=42.569, p \leq .001, \eta^{2}=.228\right)$. Pairwise comparisons further showed that i) Turkish students were much more concordant to the Turkish $(M=.80, S E=.024)$ than to the Belgian emotional patterns $\left(M=.64, S E=.021 ;\right.$ Mean diff $\left.=-.160, S E_{\text {mean diff }}=.012, p \leq .001\right)$; that ii $)$ Belgian majority members were markedly more concordant with Belgian average patterns ( $M$ $=.74, S E=.039)$ than with Turkish average patterns $(M=.66, S E=.044 ;$ Mean diff $=.081$, $\left.S E_{\text {mean diff }}=.022, p \leq .001\right)$; and iii) that these differences between both types of fit were much smaller for the two groups of Turkish Belgians. More specifically, Turkish first generation minorities fitted slightly better with the Turkish $(M=.68, S E=.049)$ than with the Belgian patterns $\left(M=.62, S E=.044 ;\right.$ Mean diff $\left.=-.055, S E_{\text {mean diff }}=.025, p=.029\right)$, and Turkish second generation minorities fitting slightly better with the Belgian $M=.65, S E=.037$ ) than with the Turkish patterns $\left(M=.61, S E=.041 ;\right.$ Mean diff $\left.=.042, S E_{\text {mean diff }}=.021, p=.046\right)$.

In addition to this strong interaction effect between Culture and Type of Emotional Fit, there were some smaller, yet significant effects. First, there was a main effect of Type of Emotional Fit (Pillai's Trace $=.011, F_{(1,433}=4.863, p=.028, \eta^{2}=.011$ ), indicating that, on average, concordance to the Turkish pattern was somewhat higher than concordance to the Belgian pattern, which may be due to the larger number of Turkish students in this analysis. Second, there was a significant three-way interaction between Type of Emotional Fit, Valence and Culture (Pillai's Trace $=.079 F_{(1,433}=12.375, p \leq .001, \eta^{2}=.079$ ), indicating that the reported effects were more outspoken for negative than for positive situations. Finally, there 
was a significant three-way interaction between Type of Emotional Fit, Context and Culture (Pillai's Trace $\left.=.025 F_{(1,433}=3.759, p=.011, \eta^{2}=.025\right)$, suggesting that, with the exception of Turkish first generation minorities, the differences between both types of concordance were more outspoken in the work context than in the family context. 
ONLINE SUPPLEMENTARY MATERIALS: EMOTIONAL FIT WITH THE HERITAGE CULTURE

Table 1A.

List of emotion items included in the Emotional Patterns Questionnaire.

\begin{tabular}{l|l}
\hline Study 1 & Study 2 \\
\hline Upset & Upset \\
Guilty & Guilty \\
Irritated & Irritated \\
Ashamed & Ashamed \\
Afraid & Afraid \\
Interested & Interested \\
Proud of myself & Proud of myself \\
Strong & Strong \\
Bored & Bored \\
Ill feelings to another & Ill feelings to another \\
Jealous & Jealous \\
Close & Close \\
Respect & Respect \\
Indebted & Indebted \\
Feel like relying on another & Feel like relying on another \\
Feel resigned & Feel resigned \\
Helpful & Helpful \\
Wurprised & Surprised \\
Embarrassed & Worthless \\
\hline & Embarrassed \\
\hline
\end{tabular}

Note. Items in bold are those that were found to be not structurally equivalent across the immigrant minority and new majority culture's samples (according to a Simultaneous Coponent analysis, see De Leersnyder, Mesquita \& Kim, 2011) and that were thus removed from the patterns before calculating emotional fit scores. 
ONLINE SUPPLEMENTARY MATERIALS: EMOTIONAL FIT WITH THE HERITAGE CULTURE

Table 2A.

Hierarchical Multiple Regression Analyses Predicting Immigrants' Emotional Fit with the Heritage Culture's Average Emotional Patterns.

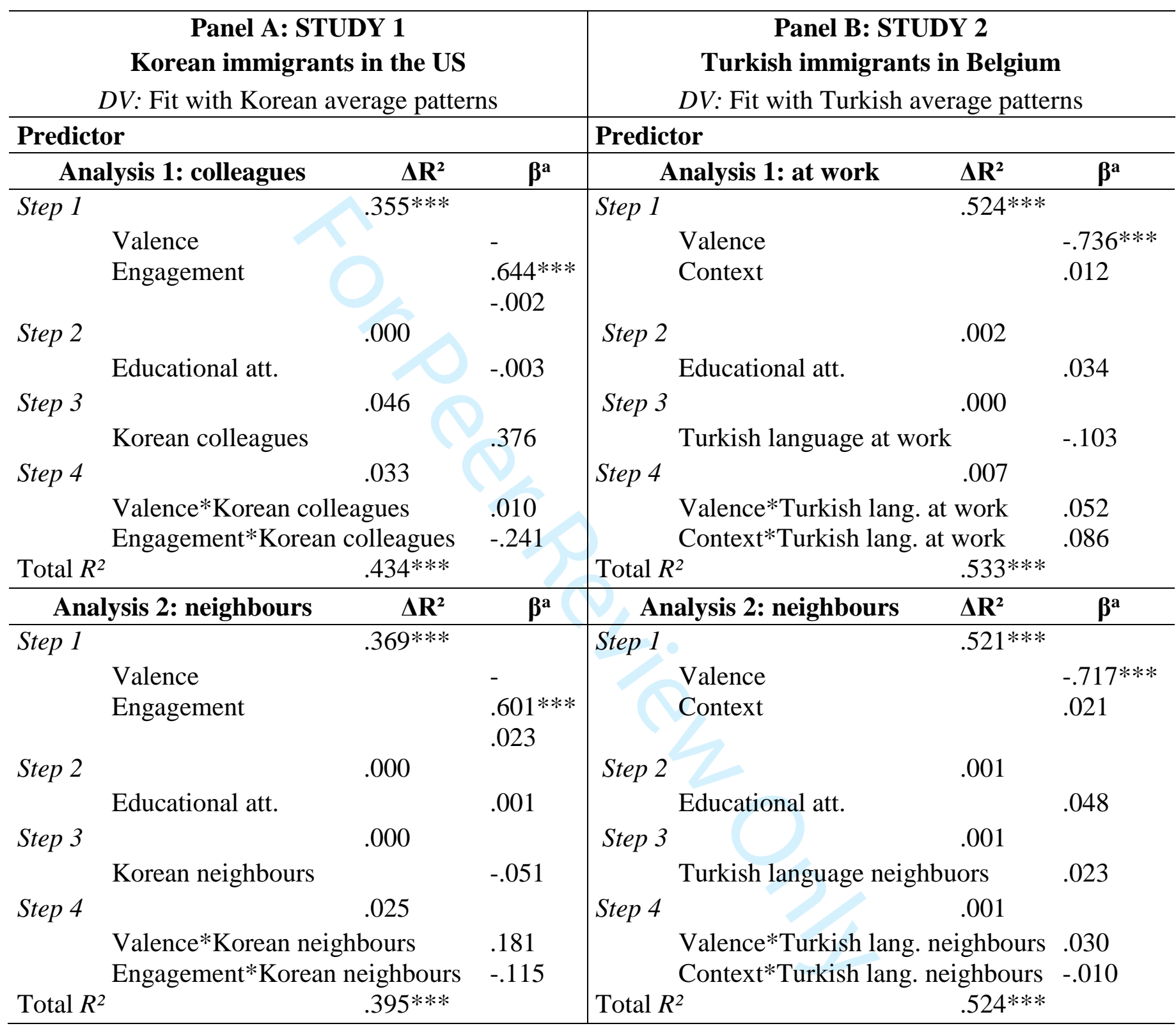


Table A2. continued

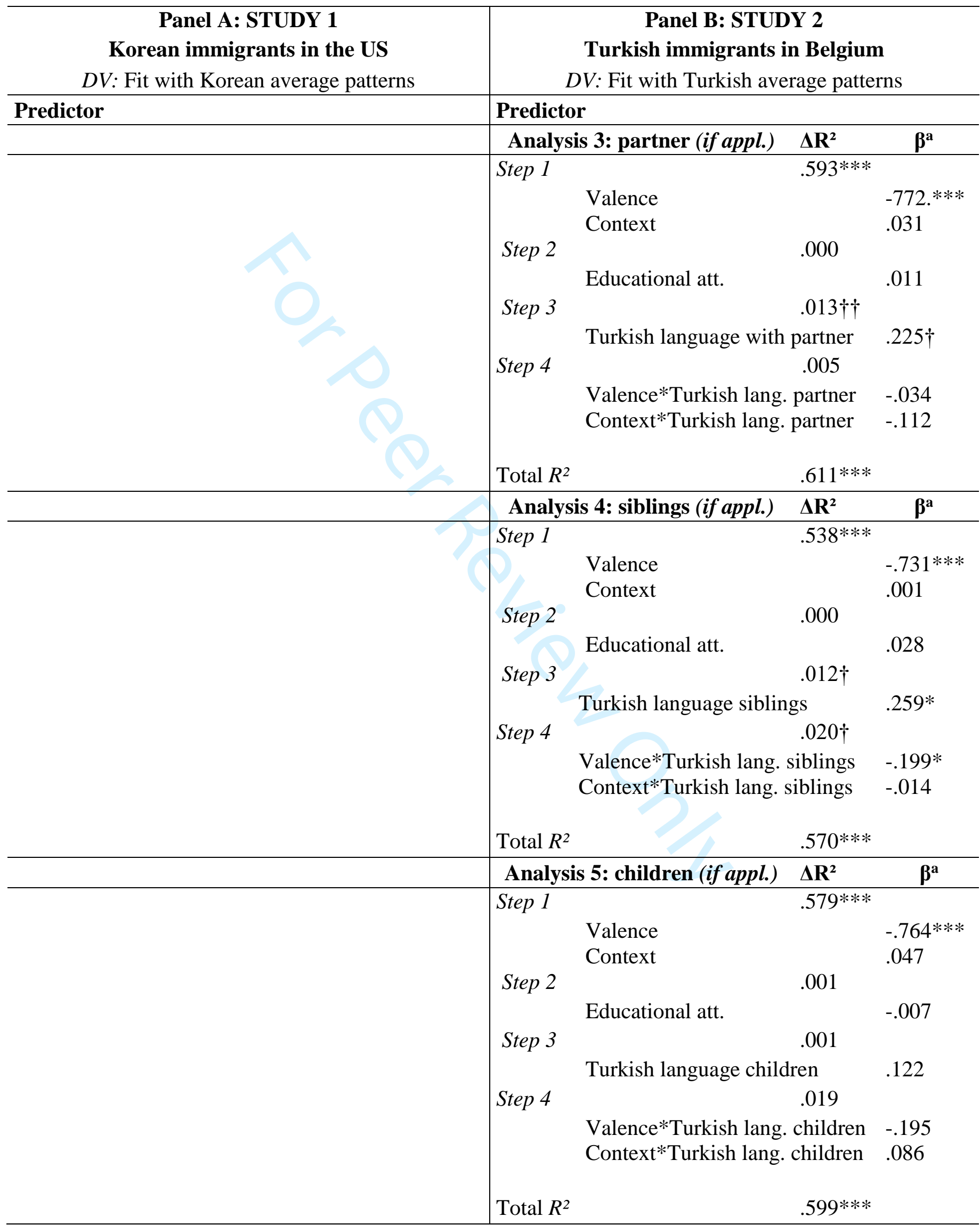


Table A2, continued

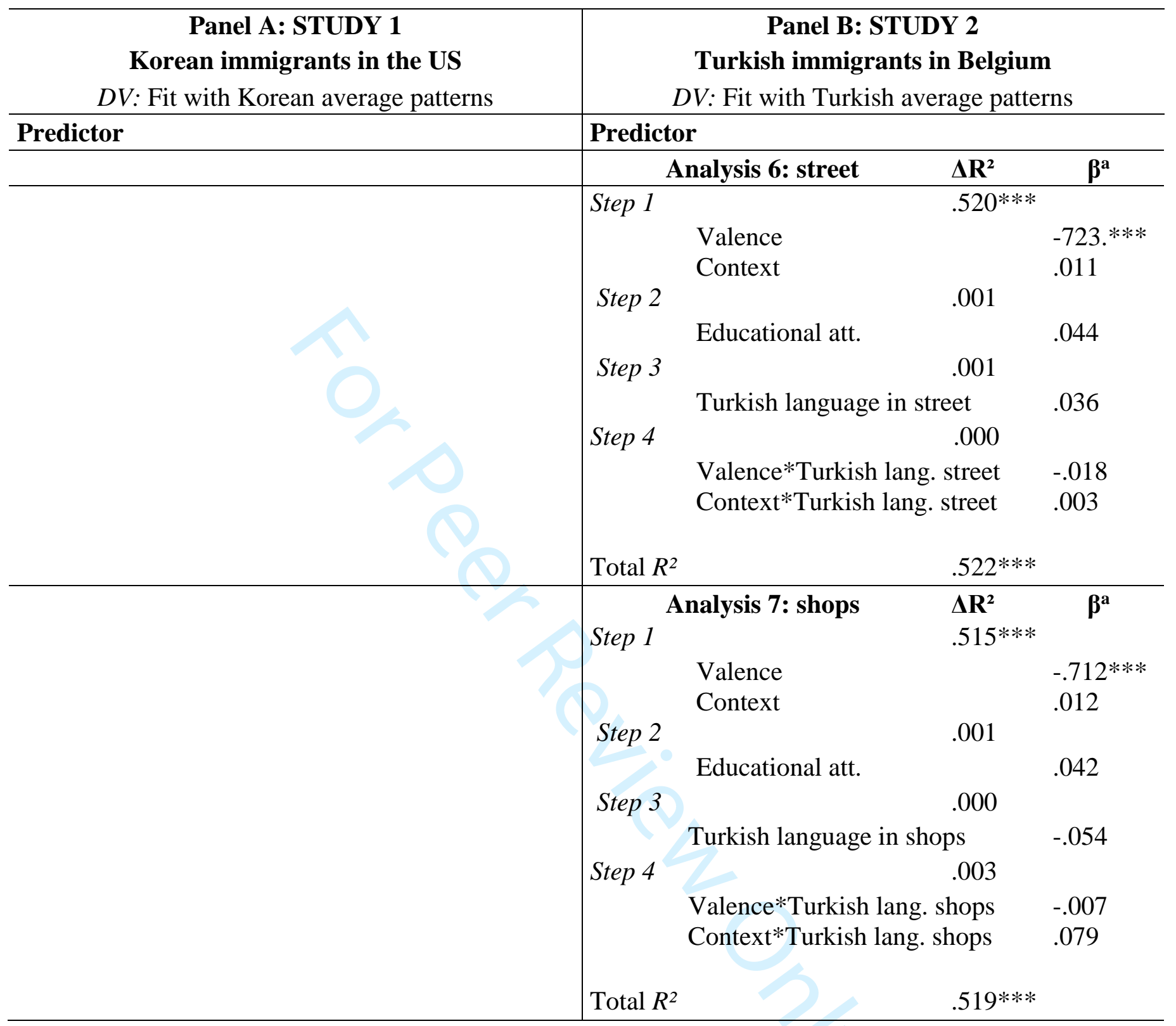

Note. ${ }^{a}$ The $\beta$ 's presented here are the ones from the fourth regression model, i.e. the one that included the interaction effects between Valence and the predictor of interest and Engagement (Study 1) or Context (Study 2) and the predictor of interest. We chose to present this model as none of the models including step 3, 4, 5, or 6 reached significance and this fourth model does allow to infer the simple main effects (see $\beta$ 's presented in step 3) and two-way interactions (step 4), while avoiding complex three-way interactions that did not reach significance anyway (step 5 and 6 are not shown). Full results of all other types of models can be obtained upon request from the first author.

$\dagger \dagger p \leq .150 ; \dagger p \leq .100 ; * p \leq .050 ; * * p \leq .010 ; * * * p \leq .001$ 
RUNNING HEAD: EMOTIONAL FIT WITH THE HERITAGE CULTURE

\title{
Submitted to: Cognition and Emotion
}

\section{My Emotions Belong Here and There:}

Extending the Phenomenon of Emotional Acculturation to Heritage Culture Fit.

\author{
Jozefien De Leersnyder \\ University of Leuven \\ Heejung S. Kim \\ University of California, Santa Barbara \\ Batja Mesquita \\ University of Leuven
}

Words: 96619855

\begin{abstract}
Author's Note
Jozefien De Leersnyder \& Batja Mesquita, Center for Social and Cultural Psychology, University of Leuven; Heejung Kim, Department of Psychological and Brain Sciences, University of California Santa Barbara.

This research was supported by research funds from the University of Leuven to the last author and by an FWO post-doctoral grant that was awarded to the first author (grant number: 12L7816N).

Correspondence concerning this article should be addressed to Jozefien De Leersnyder or Batja Mesquita, Center for Social and Cultural Psychology, Tiensestraat 102, bus 3727, 3000 Leuven, Belgium. Email: Jozefien.DeLeersnyder@kuleuven.be; mesquita@kuleuven.be

We thank Berna Coker and her colleagues from the Buça Eğitim Facultesi at the Doküz Eylül Üniversitesi in Izmir and Joke Van Eylen for their support during our data-collection in Turkey. We also thank Kimin Eom and Hyewon Choi for collecting the data in Korea.

The data and SPSS-syntax that support the findings of these studies are available from the corresponding author, [JDL], upon reasonable request.
\end{abstract}


RUNNING HEAD: EMOTIONAL FIT WITH THE HERITAGE CULTURE

\begin{abstract}
When immigrant minorities engage in a new cultural context, their patterns of emotional experience come to change - a process we coined emotional acculturation (De Leersnyder, Mesquita, \& Kim, 2011). To date, research on emotional acculturation focused on the antecedents and consequences of changes in minorities' fit with the new culture. Yet, most minorities also continue to engage in their heritage culture. Therefore, the current research investigated which personal and situational factors afford minorities to maintain emotional fit with their heritage culture. Two studies compared the emotional patterns of Korean Americans $(n=49)$ with those of Koreans in Korea $(n=80)$, and the emotional patterns of Turkish Belgians ( $n=144)$ with those of Turks in Turkey $(n=250)$, respectively. As expected, we found that although minorities did not fit the heritage emotional patterns as well as participants in their home countries, spending time with heritage culture friends and interacting in heritage culture settings explained within-group differences in minorities' heritage culture fit. Therefore, the current research shows that minorities' emotional patterns are not only cultivated, but also activated by their interactions in different socio-cultural contexts. Moreover, it provides initiat further evidence for cultural frame-switching in the domain of emotion.
\end{abstract}

Words: 200

Keywords: Emotional acculturation; emotion; culture; acculturation; cultural frame switching, cultural fit 
RUNNING HEAD: EMOTIONAL FIT WITH THE HERITAGE CULTURE

\section{My Emotions Belong Here and There:}

\section{Extending the Phenomenon of Emotional Acculturation to Heritage Culture Fit.}

Emotional acculturation refers to the process of changes in one's emotional life that are due to sustained contact with another culture (De Leersnyder, 2017). Indeed, the more immigrant minorities engage in a new culture, the more their patterns of emotion come to fit with the typical patterns of that culture (Consedine, Chentsova-Dutton, \& Krivoshekova, 2014; De Leersnyder, Mesquita, \& Kim, 2011; Jasini, De Leersnyder, Phalet, \& Mesquita, 2019) - fit that is positively associated with well-being (Consedine et al., 20014; De Leersnyder, Kim, \& Mesquita, 2015; De Leersnyder, Mesquita, Kim, Eom, \& Choi, 2014). However, since many (if not most) immigrant minorities not only engage in their new socio-cultural environment, but also continue to be part of social networks and communities that represent their heritage culture (van den Broek \& van Ingen, 2008), emotional acculturation may not only pertain to adopting a new culture's emotional patterns, but also to preserving one's heritage culture's patterns.

To date, no studies have investigated minorities' emotional fit with their heritage culture. Therefore, the current research addresses which personal and situational factors foster Korean Americans (Study 1) and Turkish Belgians (Study 2) to maintain their heritage culture's emotional patterns. As personal factors, we investigated which specific aspects of minorities' engagement in the heritage culture predict their heritage culture emotional fit. Is it a matter of having been exposed to the heritage cultural context? Or rather a matter of having heritage culture friends? As situational factor, we tested if the cultural setting of interaction matters for emotional fit. Do minorities have a higher fit with heritage emotional patterns when they interact in heritage culture settings, such as at home?

By addressing these questions, the current research aims to contribute to our understanding of emotional acculturation as a multi-dimensional and context-dependent process of emotional adaptation. Simultaneously, it aims to contribute to our understanding of 
emotion itself. For instance, if we were to find that minorities' emotional fit with their heritage culture is a function of their heritage culture engagement, this would provide further support for the idea that people's cultural engagements shape their emotional experiences (Mesquita, 2003; Mesquita, Boiger, \& De Leersnyder, 2017). Furthermore, if minorities would fit heritage emotional patterns better in heritage culture settings, this would suggest that people construct their emotional experiences 'in the moment' to be in line with the prevailing cultural context (Boiger \& Mesquita, 2012; Mesquita, Boiger, \& De Leersnyder, 2016).

\section{Cultural differences in emotional patterns}

The main starting point for research on emotional acculturation are the well-documented and systematic cultural differences in people's emotional experiences (Kitayama, Mesquita, \& Karasawa, 2006; Mesquita, 2003; Tsai, Knutson, \& Fung, 2006). For instance, experiences like pride, anger, or irritation that afford autonomy and independence and that have been called socially disengaging or autonomy-promoting emotions (De Leersnyder, Koval, Kuppens, \& Mesquita, 2018) tend to be most prevalent and intense in cultural contexts that value independence and autonomy, such as European American middle class contexts. In contrast, experiences like feeling close, ashamed or indebted that encourage relatedness and interdependence and that have been called socially engaging or relatedness-promoting emotions, tend to be most prevalent and intense in cultural contexts that value interdependence and relatedness, such as in Japanese and Mediterranean contexts (e.g., Boiger, Mesquita, Uchida, \& Barrett, 2013; Boiger, Güngör, Karasawa, \& Mesquita, 2014; Kitayama et al., 2006; Markus \& Kitayama, 1991; Rothbaum, Pott, Azuma, Miyake, \& Weisz, 2000). Thus, emotions that match a culture's central goals and values tend to be experienced more frequently and intensely than emotions that do not.

Building on these findings, we may expect that different cultural contexts are characterized by different 'typical' patterns of emotional experience and that individuals who 
engage in the same cultural context - and, therefore, are exposed to the same meanings and practices - experience more similar patterns of emotion than people who engage in different cultural contexts. Furthermore, we may expect that the emotional patterns of immigrant minorities may be initially different from those that are typical for their new majority culture, yet come to be aligned with them upon increased engagement in the majority culture - that is, that people's emotional patterns may acculturate.

\section{Emotional acculturation towards the new majority culture patterns of emotion}

There is now strong evidence for emotional acculturation, with several large scale studies on different minority groups in both the United States and Belgium that documented that minorities' engagement in a new cultural context is positively associated with their emotional fit to that context (Consedine et al., 2014; De Leersnyder et al., 2011; Jasini et al., 2019). Firstly, whereas first generation immigrants had significant lower emotional fit with the majority culture than majority members themselves, fit levels seemed to increase for each later generation. This finding was most outspoken for negative situations and resonates with the general observation that emotional fit tends to be higher in (typically more straightforward) positive than in (typically more complex) negative situations (see De Leersnyder et al., 2011 for a discussion on this issue).

Secondly, minorities' emotional fit (in both positive and negative situations) was higher to the extent they were more exposed to the majority culture (i.c. were younger at the time of migration; have spent more years) and had more social interactions with majority members. Zooming in on this latter link, a recent large-scale social network study on immigrant minority youth showed that although their emotional fit with the majority was predicted by both outgoing and incoming ties with majority peers, it was most strongly predicted by bi-directional ties, which signal reciprocity and thus 'true friendship' (Jasini, De Leersnyder, Kende, et al., submitted). This latter finding suggests a potential special function of close friends in learning 
and maintaining emotional patterns: It is perhaps in the (safe and open) context of friendships that people mostly share emotional episodes with one another and that they get reinforced or questioned about the meanings and experiences they associate with these episodes.

Finally, minorities' emotional fit with the majority culture was unrelated to their attitudes towards adopting the majority culture's values and traditions (De Leersnyder et al., 2011; Jasini, et al., 2019). Though counterintuitive at first sight, this finding is in line with the ideas that i) "explicit beliefs [attitudes] may be quite independent of implicit psychological tendencies [emotions]" (Kitayama \& Imada, 2010, p. 186), and that ii) different domains may acculturate at a different pace or even in different directions (Mesquita, De Leersnyder, \& Jasini, 2019; Schwartz, Unger, Zamboanga, \& Szapocznik, 2011; Snauwaert, Soenens, Vanbeselaere, \& Boen, 2003). Taken together, past research thus suggests that minorities' emotional fit with the typical majority patterns is a function of their actual rather than their desired engagement in the majority culture.

\section{Emotional acculturation and heritage culture patterns of emotion}

Notwithstanding the importance of minorities' fit with the majority culture, we may not lose sight of the potential multi-dimensional nature of the emotional acculturation process. As mentioned above, most immigrant minorities not only engage in majority contexts, but continue to engage in heritage contexts on a daily basis, be it through family members, friends, or the ethnic composition of their neighbourhood (van den Broek \& van Ingen, 2008). If emotional experiences, then, are a function of socio-cultural engagements, both majority and heritage culture engagement should shape emotional patterns. Moreover, and grounded in research that showed minorities' potential for simultaneous endorsement of positive attitudes towards both the majority and heritage cultures (Berry, 1997; Ryder, Alden, \& Paulhus, 2000), it may well be that they can come to fit the emotional patterns of the new majority culture without losing fit with the heritage culture. If so, minorities may furthermore alternate between majority and 
RUNNING HEAD: EMOTIONAL FIT WITH THE HERITAGE CULTURE

heritage emotional patterns depending on their context of interaction, just like they do in the domains of identity and cognition (e.g., LaFromboise, Coleman, \& Gerton, 1993; Hong, Morris, Chiu, \& Benet-Martinez, 2000). Thus, to gain insight into the (complexities of the) process of emotional acculturation, it may be fruitful to study minorities' heritage culture fit and, more specifically, to identify both the personal and situational factors that foster this fit.

Personal factors. To identify personal factors associated with minorities' heritage culture fit, we build on the studies on majority culture fit reviewed above. Firstly, we expect group differences in people's emotional fit to the heritage culture (H1), such that this is highest for majority members living in the home country (i.c., Koreans in Korea, Turks in Turkey), lowest for majority members from the new majority context who are unlikely to have spent time in minorities' home country (i.c., European Americans and Belgians), and somewhere 'in between' for immigrant minority groups, with first generation minorities having slightly higher fit to the heritage culture than later generation minorities.

Secondly, we expect that minorities' heritage culture fit is positively associated with their direct exposure to the heritage culture (H2) as measured by i) the number of years spent in the heritage culture and ii) the percentage of time spent in the heritage versus new majority context.

Thirdly, we expect that minorities' emotional fit with the heritage culture is a function of their social contacts with heritage culture members (H3) as measured by composite scores of i) the number of colleagues, friends and neighbours that have a heritage cultural background, (which is a direct index of the ethnicity of one's social contacts), and/or ii) whether one speaks one's heritage language with family members, colleagues, friends, neighbours, etc., (which is an indirect index of whether one interacts with heritage versus majority culture members).

Finally, we expect that minority members' explicitly formulated attitudes towards the heritage cultural values and traditions will not predict heritage culture fit (H4), because 
emotional fit - as a rather implicit measure of minorities' cultural affiliation - may change at a different pace, or even in a different direction, than explicitly endorsed attitudes.

However, since most immigrant minorities live in ethnic enclaves, and the participants of this research were no exception to this, we may think of two alternative hypotheses that do not mirror the findings on majority culture fit. Firstly, since ethnic enclaves expose their residents to (a form of) heritage cultural ideas and practices on a daily basis, the time or proportion spent in the country of origin may not substantially add to minorities' exposure to the heritage culture (H2A). Secondly, minority groups may be very homogenous in the extent to which they have contact with heritage culture family members, colleagues and neighbours, which lowers their predictive value. Therefore, only social contact with heritage culture friends, which already have a special status in relation to (re)shaping emotional experience (Jasini, et al., submitted), may be the best (if not the only) personal factor predicting heritage culture emotional fit (H3A). The current research will explore which one of these two sets of hypotheses fit the data best.

Situational factor. The second aim of this research is to test if immigrant minorities' emotional patterns depend on the situation and, more specifically, the socio-cultural context in which they are experienced. Indeed, biculturals may display different psychological tendencies and behaviours when being primed with their heritage versus new majority culture - a phenomenon that is commonly referred to as cultural frame switching (Hong, Morris, Chiu, \& Benet-Martínez, 2000) and that has been extensively documented in various psychological domains (e.g., Hong et al., 2000; Ramírez-Esparza, Gosling, Benet-Martínez, Potter, \& Pennebaker, 2006; Briley, Morris, \& Simonson, 2005), except for emotion. In fact, evidence is limited to one study (Perunovic, Heller, \& Rafaeli, 2007) showing that East Asian Canadians' momentary positive and negative moods were less (rather than more) negatively correlated after having spoken an Asian language or having identified with their heritage culture, which is in 
line with an Asian (rather than Western) dialectical emotional style. Therefore, we hypothesize that when minorities report emotional patterns that took place in heritage culture settings, like one's home, these will be more concordant to the typical heritage cultural patterns than those that were experienced in majority settings, like one's school or workplace (H5).

\section{Current studies}

Data. To investigate the above outlined hypotheses, we extend previous research on immigrants' adoption of the new culture's emotional patterns (De Leersnyder et al., 2011), by studying the same immigrant groups in terms of their maintenance of heritage culture emotional patterns. These previous studies focused on (mainly first generation) Korean Americans (Study 1) and first and second generation Turkish Belgians (Study 2), each time comparing their emotional patterns to those of their respective majority cultural groups (European Americans and Belgians). In the current research, we collect new data to compare minorities' emotional patterns to those of their heritage cultural groups, i.e. Korean and Turkish majority members in Korea and Turkey, respectively. Hence, the here reported analyses are novel and in no sense similar to what we have analysed and reported in previous work.

Cultural groups under study. We chose the target minority and majority groups on the basis of two criteria. First, and to maximize the prospect of observing acculturative shifts in minorities' emotional patterns, we chose majority and minority groups that differ in their typical emotional patterns (see Kitayama et al., 2006; Mesquita, 2001). Second, and to maximize the potential for analytic inference from these case studies to a more general theory on emotional acculturation, we selected two minority groups that are very different in their socio-economic statuses, migration histories and diversity contexts. ${ }^{1}$ Hence, Study 1 and Study 2 are theoretical

\footnotetext{
${ }^{1}$ Korean Americans are more highly educated and better employed than Turkish Belgians (FOD Werkgelegenheid, 2009; Terrazas, 2009) and face a racial rather than a religious 'divide' whereas the opposite is true for Turkish Belgians (Alba, 2005; Yoo \& Chung, 2009). Moreover, both groups navigate very different
} 
replications of one other, enabling us to be more confident in drawing conclusions about the personal and situational factors that afford minorities to maintain their heritage culture patterns of emotion.

\section{Study 1}

Study 1 was designed to test our hypotheses in a sample of Korean Americans. To calculate their emotional concordance to their heritage culture's typical patterns of emotional experience, we collected data from Koreans in South Korea.

\section{Method.}

Participants. Participants were 49 Korean Americans, of whom 37 were first generation immigrants who had spent about half of their lives in Korea $\left(M_{\text {proportion_life_Korea }}=0.54, S D=\right.$ 0.34), and 44 European Americans; both were available from earlier research (De Leersnyder et al., 2011). For the purpose of this research, we additionally sampled 80 Koreans living in South Korea. The three samples were comparable in terms of self-reported social class, education and gender composition (See Online Supplementary Materials for full statistics), but Koreans were younger $\left(M_{\text {age }}=27.9 ; S D_{\text {age }}=4.3\right)$ than both Korean Americans $\left(M_{\text {age }}=38.2\right.$; $S D_{\text {age }}=12.8 ;$ Mdiff $\left.=-10.317 ; t_{(50.96)}=-5.280, p \leq .001\right)$ and European Americans $\left(M_{\text {age }}=37.6\right.$; $S D_{\mathrm{age}}=16.6 ;$ Mdiff $\left.=-9.762 ; t_{(43.95)}=-3.741, p=.001\right)$.

Controlling for Gender, Age, Class, or Educational Attainment did not alter the results. Yet, in order to keep the current series of analyses consistent with those on minorities' adoption of new majority emotional patterns, (De Leersnyder et al., 2011), we excluded one Korean American who had received none or only primary education and controlled for Educational Attainment in our analyses (dummy coded as $0=$ "secondary education"; $1=$ "tertiary education"). We further excluded two Korean Americans who failed to report situations that

acculturation environments because immigration patterns, discourses, institutions and policies differ substantially between the United States and Belgium (Kosic \& Phalet, 2006; Van Acker, 2012). 
RUNNING HEAD: EMOTIONAL FIT WITH THE HERITAGE CULTURE

matched the valence of the prompts, which prevented us from calculating their emotional fit (see below).

Materials. Emotional Patterns Questionnaire (EPQ). To capture people's emotional fit with culture, we administered the EPQ (De Leersnyder et al., 2011), which asks participants to describe a recently experienced emotional situation that matches a prompt. Prompts vary on the dimensions of valence (positive vs. negative), social engagement (socially disengaging/autonomy-promoting vs. socially engaging/relatedness-promoting) and relational context (home/family vs. work/school). For example, the prompt for positive disengaging situations in work/school contexts read: "Please think about an occasion at work or at school in which you felt good for yourself. For example, you felt superior, proud, top of the world". After describing such a situation, participants were asked to rate the intensity (from $1=$ "Not at all" to $7=$ "Extremely") of their experience in that situation on a set of 20 emotion scales that cover the emotional domain in terms of valence and social engagement (see Online Supplementay Materials Table 1A). These data constitute a participant's emotional pattern for a given situation.

To calculate emotional fit with the heritage culture, we took the following steps. Firstly, we removed three emotion items from participants' emotional patterns because a Simultaneous Component Analysis (De Roover et al., 2012) had indicated that only the 17 other items were structurally equivalent across Korean and European American samples (see De Leersnyder et al., 2011 for full results). Secondly, we established the average Korean emotional patterns for

${ }^{2}$ In both Study 1 and Study 2 we employed a Simultaneous Component Analysis (SCA; De Roover et al., 2012) to assess structural equivalence of the emotion data. This analysis provides insight into i) whether one common factor solution can be used across the different samples under study and ii) which items load on different factors, $\underline{\text { implying that they are not structurally equivalent and hence, differently understood across the cultural groups. For }}$ instance, in Study 2, "feeling resigned" loaded on the negative autonomy-promoting emotion component in the 
RUNNING HEAD: EMOTIONAL FIT WITH THE HERITAGE CULTURE

each type of prompt (e.g., for positive autonomy-promoting situations at work/school) by averaging the emotion ratings from all Korean majority members who had responded to that prompt. As such, we obtained eight different Korean average patterns of emotion, one for each type of prompt. Thirdly, we calculated Korean American's and European Americans' emotional concordance or fit to the average Korean patterns by correlating each individual's pattern to the corresponding (i.e., same situation-type) Korean average pattern. To calculate Korean majority members' fit with their own culture's average patterns, we correlated each individual's pattern of emotion to a pattern that consisted of all other Koreans' scores and thus excluded the participants own score from the average. In this way, we avoided an artificial inflation of Koreans' concordance scores; individuals' patterns are never correlated to an average pattern they have contributed to themselves. Fourthly, we transformed all correlation scores into Fisherz scores to ensure linearity, which is required for further analyses.

Finally, we aggregated participants' Fischer z-scores to obtain one mean emotional concordance variable. However, because of logistical reasons, Korean majorities completed four versions of the EPQ, with each prompt pertaining to a different type of valence*engagement within the same relational context (either home/family $(n=40)$ or work/school $(n=40))$, whereas Korean Americans and European Americans had completed two versions of the EPQ, with prompts that pertained to same type of valence*engagement, but differed across relational contexts (i.e., one in a work/school context; the other in a home/family

Belgian sample, but loaded on both the negative autonomy-promoting and the positive relatedness-promoting components in the Turkish Belgian samples. Personal conversations with Turkish Belgian participants explained

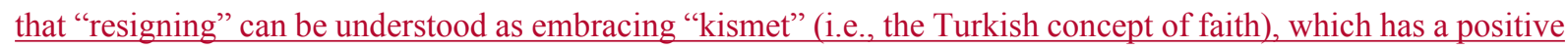
connotation in the Turkish cultural context. Although these cultural differences are interesting in itself, we removed items like this from the emotional patterns before calculating 'fit', because any (cultural) difference in intensity on these items may be due to their different meaning, while 'fit' is about the (cultural) differences in patterns of intensity across emotions that have similar meanings across the groups under study. 
RUNNING HEAD: EMOTIONAL FIT WITH THE HERITAGE CULTURE

context). This implies that Korean majorities' overall emotional fit score was the average of four fit scores, whereas those of Korean Americans and European Americans was the average of only two.

Personal Factors of Cultural Engagement. Korean Americans' exposure to Korean culture was captured by the Number of Years and their Proportion of Life spent in the heritage culture. The scale capturing Korean Americans' degree of Social Contact with Heritage Culture Members consisted of three items $(\alpha=.74)$ that asked about the ethnicity of their friends, colleagues, and neighbors, respectively (on a scale from $1=$ "heritage culture only" to $5=$ "Euro-Americans only"). We recoded all items such that higher scores indicated more social contact with Koreans $(M=3.01(S D=0.88)$.

Korean Americans' acculturation attitudes were measured by 8 items from the Vancouver Index of Acculturation (Ryder et al., 2000), with scales ranging from 1 (totally disagree) to 9 (totally agree). A Principal Component Analysis yielded two different factors that formed the basis of two scales: Attitudes toward the Maintenance of Values and Traditions (four items, $\alpha=.78 ; M=6.28, S D=1.55$; Example: "It is important for me to maintain or develop Korean cultural practices") and Attitudes toward Social Contacts with Heritage Culture Members (four items, $\alpha=.77 ; M=7.29, S D=1.35$; Example: "I am interested in having Korean friends"). The two scales were significantly correlated with each other $(r=.523, p \leq .001)$.

Situational factor of Cultural Engagement: Our situational factor is the socio-cultural context in which the situation took place (as specified by the prompt): either at home/with family versus at work/school. We consider the home/family context as representative for the heritage culture since most minorities have family members with a heritage culture background, and consider the work/school context as representative for the new majority culture since most of minorities' colleagues/classmates have a majority cultural background. 
Procedure. Before participating, participants received, read, and signed an informed consent (approval granted by the Human Subjects Committee, University of California at Santa Barbara). Korean Americans and European Americans had been recruited in public places, such as malls, churches, and coffee shops in Southern California, where Korean Americans live in immigrant neighbourhoods (see De Leersnyder et al., 2011). Koreans in Korea were recruited through a Christian mega-church because $91 \%$ of Korean Americans self-identify as Christians (Yoo \& Chung, 2009) and we wanted the Korean sample to be similar in this regard. Korean participants received $\$ 10.000$ (about \$10) for completing the questionnaires in Korean.

\section{Results.}

Analytic strategy. To assess how personal factors were associated with heritage culture emotional fit (i.e., to test $\mathrm{H} 1-\mathrm{H} 4$ ), we made use of participants' aggregated emotional fit scores with the Korean typical patterns of emotion. To test group differences in participants' emotional fit (H1), we conducted an ANOVA that predicted all participants' fit score from their group membership. To test if minorities' emotional fit with the Korean patterns was predicted by their exposure (H2) or not (H2A) and general level of social contact with Koreans (H3) versus only by the number of heritage culture friends (H3A), we conducted a carefully planned series of hierarchical linear regression analyses. The dependent variable was always Korean Americans' fit with the typical Korean patterns of emotion, yet separate regressions were run for each 'predictor of interest', resulting in 4 different analyses to test the 4 main hypotheses (i.e., Regression 1: Number of Years in Korea; Regression 2: Proportion of Life in Korea; Regression 3: Social Contact Koreans; Regression 4: Acculturation Attitudes; see also Table 1) and 3 additional ones to test H3A. The first two blocks of each regression included our control variables, namely Valence and Engagement as the between-subject variables in our design (Block 1) and Educational Attainment (Block 2). Block 3 always included our predictor of interest. Whereas Block 4 tested all two-way interactions between the specific predictor of 
interest (as entered in Block 3) and Valence and Engagement, Block 5 did so for the two way interaction between the predictor of interest and Educational Attainment. Finally, Block 6 tested the 3-way interaction between the specific predictor of interest, Valence, and Engagement.

To assess the influence of the situational factor on heritage culture emotional fit (H5), which requires to compare Korean Americans' fit with the Korean versus the European American average patterns of experience, we relied on Korean Americans' fit scores with both the average Korean patterns and those with the average European American patterns established in previous work (De Leersnyder et al., 2011). Moreover, because this hypothesis requires a comparison at the level of the relational context (home/with family vs. work/school) and this was a within-subjects factor, we used participants' unaggregated fit scores. Specifically, we ran two paired-samples t-tests (one for home/family context; the other for work/school context) that each time compared Korean Americans' fit with the typical Korean pattern to their fit with the typical European American pattern.

Personal factors: Which aspects of heritage engagement predict Korean Americans' heritage emotional fit? At the group level, we had hypothesized that emotional fit to the typical Korean patterns would be higher for the Korean majority group than the Korean American and European American groups (H1). Consistently, an ANOVA yielded group differences in mean emotional fit $\left(F_{(2,163)}=16.698 ; p \leq .001, \eta^{2}=.170\right)$. Pairwise comparisons showed that Koreans in Korea fitted the typical Korean pattern significantly better $(M=1.05$; $S D=.28)$ than European Americans $\left(M=.63 ; S D=.50 ; M_{\text {diff }}=.42 ; p \leq .001,95 \%\right.$ CI: $[.263$, $573])$ and Korean Americans $\left(M=.74 ; S D=.50 ; M_{\text {diff }}=.31 ; p \leq .001,95 \%\right.$ CI: [.156, .459]). The fit scores of Korean Americans fell nicely in between those of Koreans and European Americans, yet were not significantly higher than those of European Americans (see Figure 1, left panel). 
RUNNING HEAD: EMOTIONAL FIT WITH THE HERITAGE CULTURE

At the individual level, we explored the two contrasting sets of hypotheses outlined in the Introduction. On the one hand, we had hypothesized that engagement in the heritage culture would predict heritage emotional fit ( $\mathrm{H} 2 \& \mathrm{H} 3)$; on the other hand, the alternative hypotheses stated that the operationalisations of cultural exposure (number of years and proportion of life spent in heritage culture) would not be associated with immigrants' emotional fit (H2A) and that fit would be only predicted by one's number of Korean friends (H3A).

As described above, we tested these predictions by conducting a series of four hierarchical linear regressions to test $\mathrm{H} 2-\mathrm{H} 4$ and three additional ones to test $\mathrm{H} 3 \mathrm{~A}$. All regressions yielded a main effect of Valence (step $1 R^{2}$ change $=.369, p \leq .001 ; B$ 's ranging from -.615 to $-.580, p \leq .001$; see Table 1 , panel A), indicating that participants had significantly higher emotional fit in positive than in negative situations. The other control variables (Block 1: Engagement; Block 2: Educational attainment) did not significantly contribute to explaining variance in immigrants' Korean emotional fit, and Blocks 5 and 6 that tested all two-way and three-way interactions never yielded significant results; hence, we don't report them here (full results can be obtained from the first author).

Regressions 1 and 2 showed that Korean Americans' emotional fit to Korean patterns was neither associated with the number of years nor with the proportion of life spent in Korea (all $p>.10$; for the full results, see Table 1, panel A, Regressions 1 and 2), which renders support for $\mathrm{H} 2 \mathrm{~A}$ instead of $\mathrm{H} 2$. For minorities in ethnic enclaves (such as the ones we recruited), time spent in the heritage country does not predict heritage emotional fit, perhaps because it does not expose minorities to heritage culture's meanings and practices above and beyond what they are exposed to in their ethnic minority communities in their country of residence.

Regression 3, testing the link between heritage culture fit and social contact with heritage culture members, showed that general social contact was not predictive of emotional fit (step $3 R^{2}$ change $=.005, p=.592$, see Table 1, panel A, Regression 3 ). To test the alternative 
RUNNING HEAD: EMOTIONAL FIT WITH THE HERITAGE CULTURE

hypothesis (H3A) that only the number of Korean friends matters, we first ran Regression 3bis that included the item on having Korean friends as the predictor of interest and then another two analyses that included the item on having Korean colleagues and Korean neighbours, respectively. Confirming hypothesis $3 \mathrm{~A}$, only having Korean friends contributed significantly to Korean Americans' heritage emotional fit, be it that this effect was moderated by Valence (step $4 R^{2}$ change $=.132, p=.016, B_{\text {Valence*KoreanFriends }}=.372, p=.015,95 \%$ CI $[.076, .669]$, see Table 1, panel A, Regression 3bis). This effect was still significant after applying Bonferroni corrections for multiple comparisons $\left(p=.015<\alpha_{.05 / 3}=.017\right)$. Simple slopes indicated that the number of Korean friends was positively associated with Korean emotional fit in negative situations (simple slope $B=.208, S E=.114, p=.077,95 \%$ CI [-.023, .439]), but not in positive situations (simple slope $B=-.164, S E=, 141, p=.254,95 \%$ CI $[-.450, .122]$ ). Analyses on the number of Korean neighbours and colleagues yielded no significant results (for full results see Online Supplementary Materials, Table 2A, panel A). Supporting H3A, the only predictor of heritage culture emotional fit is thus Korean Americans' number of heritage culture friends.

In a final regression, we tested the association between Korean Americans' emotional fit with the heritage culture and the two scales that tap into their attitudes towards maintaining their heritage culture (H4). As expected, minorities' emotional fit was unrelated to their attitudes towards maintaining Korean values and traditions. However, their attitudes toward maintaining social contacts with Koreans did marginally contribute to the prediction of heritage emotional fit (see Table 1, panel A, Regression 4). To disentangle whether this is an effect of attitudes per se versus of actually having Korean friends, we conducted a post-hoc regression analysis in which both variables were the predictors of interest. It showed that whereas Korean Americans' Korean emotional fit was not predicted by their attitudes towards social contact (step $3 R^{2}$ change $\left.=.060, p=.166\right)$, it was by their actual number of Korean friends (step $4 R^{2}$ change $=.160, p=.028 ; B=.412, p=.007,95 \%$ CI [.122, .702]; see Table 1 , panel A). 


\section{Situational factor: Does interacting in Korean cultural settings afford Korean}

Americans to fit the Korean emotional patterns better? Based on the cultural frame switching literature, we had expected that minorities' interactions in home/family contexts would afford emotional experiences that fit the Korean typical patterns better than the European American ones (H5). Hence, we compared, for each context, minorities' fit to the typical European American and to the typical Korean emotional patterns by means of paired samples t-tests. For the home context, we found a marginally significant effect suggesting that Korean Americans' emotional patterns fitted better with the Korean $(M=.76, S D=.62)$ than European American patterns $\left(M=.66, S D=.56 ;\right.$ Mean_diff $=.10, S E_{\text {mean diff }}=.05, t_{(42)}=1.895, p=.065$; one-tailed $p=.033 ; 95 \%$ CI: $[-.006, .200])$. For the work/school context, however, no such difference occurred (Mean_diff $=-.01, S E_{\text {mean diff }}=.06, t_{(42)}=-.096, p=.924 ; 95 \%$ CI: [-.118, $.108]$ see Figure 2 left panel).

Post-hoc exploratory analyses suggested that the exact pattern of emotional fit levels was different for first versus second or later generation Korean Americans. Specifically, we repeated the t-tests described above, yet now for first and second or later generations separately. For the home context, we found that first generation Korean Americans fitted significantly better with the Korean $(M=.74, S D=.63)$ than European American patterns $(M=.60, S D=$ $.57 ;$ Mean_diff $=.15, S E_{\text {mean diff }}=.065, t_{(30)}=2.249, p=.032$; one-tailed $p=.016 ; 95 \% \mathrm{CI}$ : $[.013, .279])$, whereas there was no such difference for second or later generation Korean Americans (Mean_diff $=-.03, S E_{\text {mean diff }}=.062, t_{(11)}=-.488, p=.635 ; 95 \%$ CI: $\left.[-.169, .108]\right)$. In work/school contexts, however, there was a non-significant trend for later generation Korean Americans to fit better with the European American $(M=.98, S D=.49)$ than the Korean $(M=$ $.90, S D=.57)$ typical patterns $\left(\right.$ Mean_diff $=-.08, S E_{\text {mean diff }}=.087, t_{(10)}=-.947, p=.366 ; 95 \%$ CI: $[-.277, .112])$, but this was not the case among first generation minorities (Mean_diff $=.02$, $\left.S E_{\text {mean diff }}=.069, t_{(31)}=.306, p=.762 ; 95 \% \mathrm{CI}:[-.120, .162]\right)$. Given the small numbers of 
RUNNING HEAD: EMOTIONAL FIT WITH THE HERITAGE CULTURE

participants, and especially the small number of second or later generation minorities $(n=12)$, conclusions should be treated with extreme caution. Yet, these results provide some initial support for the idea that situational factors such as the context of the interaction shape minorities' emotional experiences, at least among first generation minorities.

\section{Study 2}

Study 2 was not only a replication of Study 1 in another group of minorities (Turkish) within a different host culture setting (Belgium), but also overcame several of its limitations. Concretely, Study 2 consisted of sizable samples of first and second generation minorities, which allows us to reliably compare them. Furthermore, Study 2 used a similar design of the EPQ for all groups, thereby ruling out possible design effects when comparing mean emotional fit scores across samples. Finally, in Study 2 minorities were prompted to report on two emotional situations that either occurred in the home context or in the work/school context, thereby ruling out the possibility that any evidence for emotional frame switching can be accounted for by a contrast-effect that occurs when minorities report on both contexts in the same questionnaire. All hypotheses were exactly the same as for Study 1.

\section{Method.}

Participants. Participants were 144 Turkish Belgian minorities (59 first generation; 85 second generation) and 79 Belgian majorities that were available from earlier research (De Leersnyder et al., 2011), as well as 250 Turkish majority students from the Döküz Eylül Universitesi in Izmir, Turkey, who were sampled for the purpose of this study. Across the samples there were significant differences in age, with Turkish students being significantly younger $(M=20.1, S D=1.47)$ than first generation $(M=34.1, S D=10.85)$ and second generation minorities $(M=25.59, S D=6.63)$ as well as majority Belgians $(M=31.38, S D=$ 8.67; all Mean diff were significant at $p \leq .001)$. Furthermore, the Turkish majority sample was characterized by a higher proportion of female participants $(67 \%$ females) than the other three 
samples (around 50\%; $\chi^{2}=10.338, p=.016$ ) and was less highly educated since none of the Turkish students held a tertiary education degree yet (see Online Supplementary Materials for full statistics).

However, controlling for Age, Gender, or Educational Attainment did not change the results. In order to keep them comparable to both Study 1 and our earlier work (De Leersnyder et al., 2011), we excluded three first generation minorities who had received none or only primary education and controlled for Educational Attainment in our analyses (dummy coded as $0=$ "secondary education"; 1 = "tertiary education"). We further excluded 17 participants who failed to report a situation that matched the valence of the prompts; the proportion did not differ across cultural groups $\left(\chi^{2}=2.052, p=.562\right.$; Excluded: Turkish majority $n=10$, Turkish Belgian first generation $n=2$, Turkish Belgian second generation $n=1$, Belgian majority $n=4$ ).

Materials. Emotional Patterns Questionnaire (EPQ). The EPQ used in Study 2 was identical to the one used in Study 1. However, participants from all groups now completed two versions of the EPQ that pertained to the same Relationship Context (either home/family or work/school) and Valence (either positive or negative), but differed in terms of Engagement. In order to calculate emotional fit scores, we followed the exact same procedure as in Study 1, yet now using the Turkish average emotional patterns as standard of reference with which we correlated individuals' patterns. Again, the correlations were based on only those 17 emotion items for which a Simultaneous Component Analysis indicated cross-culturally equivalence (see Online Supplementay Materials for the full list of emotions and De Leersnyder et al., 2011 for the full results of the SCA) and were transformed into Fischer z-scores. Participants' two z-scores were aggregated into one index of emotional fit with the Turkish average patterns.

Personal Factors of Cultural Engagement. Similar to Study 1, we operationalised Turkish Belgians' exposure to the heritage culture as the Number of Years and Proportion of Life spent in the heritage culture. Social Contact with Heritage Culture Members was measured 
RUNNING HEAD: EMOTIONAL FIT WITH THE HERITAGE CULTURE

through an eight item scale that asked participants whether they use to speak only Turkish (1), only Dutch (3) or both languages (2) when interacting with their partner, siblings, co-workers, neighbours, friends, etc. (De Leersnyder et al., 2011); Cronbach's $\alpha=.76$ ). We re-coded the scale such that higher scores indicate more Turkish (instead of Dutch) language use when having social contact $(M=2.00, S D=0.54)$. Since majority Belgians do not have any knowledge of Turkish, this scale is an indirect measure of the degree to which immigrants' social contacts are with heritage culture members. As an extra check, we directly asked minorities their agreement with the statement "I have a lot of Turkish friends" $(1=$ totally disagree $-7=$ totally agree $M=6.09 S D=1.44)$. We could not combine their answers with the indirect social contact scale because of the different scales.

As in Study 1, acculturation attitudes were measured by 8 items of the VIA (Ryder et al., 2000) that constituted two scales: one referring to Maintaining Values and Traditions (four items, $\alpha=.73 ; M=5.59, S D=1.17)$, the other referring to Maintaining Social Contacts with Heritage Culture Members (four items, $\alpha=.73 ; M=5.68, S D=1.17$ ). The two scales correlated substantially $\left(r_{(140)}=.68, p \leq .001\right)$, but nevertheless formed 2 factors in the PCA. ${ }^{3}$

Situational factor of Cultural Engagement: The situational factor was operationalized in the exact same way as in Study 1, namely by looking at whether the self-reported situations had taken place at home/with family versus at work/school (as defined by the prompt).

Procedure. Before each study, participants received, read, and signed an informed consent. The Belgian and Turkish Belgian community samples were recruited through centres for adult education and though flyers being distributed in (mainly) Turkish neighbourhoods in the city of Gent. The Turkish majority sample was recruited at the Educational Studies

3 Although one item did not load on the expected factor (Maintaining Values and Traditions), Cronbach's alpha got worse (instead of improved) when removing this item from the scale. Therefore, and in keeping with both Study 1 and the 2011 paper, we retained this item. 
Department of the Doküz Eylül University in Izmir, Turkey. Students volunteered in class time or during breaks.

\section{Results.}

Analytic strategy. We employed an analytic strategy that resembles the one used in Study 1. To assess group differences (H1), we conducted an ANOVA that tested differences in Turkish emotional fit between the different groups in our sample. To assess which personal factors were associated with heritage culture emotional fit, we again conducted a series of carefully planned regression analyses in which minorities' emotional fit with the Turkish patterns was predicted by their exposure to the Turkish context (Regression 1 and 2, testing H2 vs. H2A), by their general level of social contact with Turks (regression 3 testing H3) versus only by the number of heritage culture friends (regression 3 bis testing $\mathrm{H} 3 \mathrm{~A}$ ), and by their attitudes towards maintain Turkish Values and traditions and Turkish Social Contacts (Regression 4, testing H4). Again, these regressions consisted of several blocks with Blocks 1 and 2 including our control variables - i.e., the between-subject variables Valence and Relationship Context (Block 1) and participants' Educational Attainment (Block 2) - Block 3 each time including one predictor of interest and Blocks 4 to 6 testing all two-way and 3-way interactions.

To test $\mathrm{H} 5$ and thus to assess the influence of the situational factor on heritage culture emotional fit, we relied on Turkish Belgians' fit scores with both the average Turkish patterns and those with the average Belgian patterns established in previous work (De Leersnyder et al., 2011). Differently than in Study 1, the (optimised) design of Study 2 allowed us to conduct a Repeated Measures ANOVA that featured immigrants' emotional fit with the Turkish and the Belgian average patterns as dependent variables, and the Context of the prompt (home/ family vs. work/school) as predictor. In this analysis, we could also control for the (expectedly) strong 
RUNNING HEAD: EMOTIONAL FIT WITH THE HERITAGE CULTURE

valence effects and further explore whether the effects of situational engagement on emotional fit would differ across first and second generation minorities.

Personal factors: Which aspects of heritage engagement predict Turkish Belgians' heritage emotional fit? At the group level, we had hypothesized that the Turkish majority group would have higher fit to the average Turkish emotional patterns than the Turkish Belgian and Belgian groups (H1). Consistent with this hypothesis, an ANOVA yielded group differences in emotional fit $\left(F_{(3,449)}=4.099 ; p=.007, \eta^{2}=.027\right)$, showing that Turks in Turkey were significantly more concordant to the Turkish average patterns $(M=.80 ; S D=.46)$ than both Belgians $\left(M=.62 ; S D=.51 ; M_{\text {diff }}=.175 ; p=.008,95 \%\right.$ CI: $\left.[.047, .303]\right)$ and Turkish second generation immigrants $\left(M=.62 ; S D=.54 ; M_{\text {diff }}=.175 ; p=.005,95 \%\right.$ CI: $\left.[.052, .298]\right)$. The fit levels of Turkish first generation immigrants $(M=.70 ; S D=.53)$ were neither significantly lower than those of Turkish majorities $\left(M_{\text {diff }}=.104 ; p=.152,95 \%\right.$ CI: [-.038, .246]) nor significantly higher than those of second generation minorities and Belgian majorities (see Figure 1, right panel).

The regressions testing which personal factors of heritage culture engagement predict heritage culture fit, again pointed to a main effect of Valence (step $1 R^{2}$ change $=.53, p \leq .001$; $B$ ranging from -.755 to -.728, $p \leq .001$; see Table 1, panel B, Regressions $1-4$ ), indicating that emotional fit was higher in positive than in negative situations. As in Study 1, neither the other control variables (Context and Educational Attainment), nor any two-way or three-way interaction were significant; hence, we don't report on these results here (full details can be obtained from the first author).

Regressions 1 and 2 respectively revealed that neither the number of years spent in Turkey nor the proportion of life spent in Turkey predicted minorities' emotional fit with the Turkish patterns (for the full results, see Table 1, panel B), which supports the alternative H2A rather than $\mathrm{H} 2$. 
Regression 3 that predicted Turkish Belgians' heritage emotional fit from their daily social contacts with other Turkish (minority) people, found a trending effect of general social contact with Turks (step $3 R^{2}$ change $=.008, p=.139 ; B=.091, p=.139,95 \%$ CI: [-.030, .212]; see Table 1, panel B). To further explore this finding and test H3A that posited that heritage emotional fit is only a function of having heritage culture friends, we conducted an additional series of eight regression analyses in which we separately entered each individual item of the social contact scale as the predictor of interest. Supporting H3A, only Regression 3bis that included the item referring to friends yielded significant results (see Table 1, panel B): Speaking Turkish more with friends - as an indirect index of having more Turkish [minority] than Belgian majority friends - was positively associated with Turkish emotional fit (step $3 R^{2}$ change $=.029, p=.005 ; B=.116, p=.005,95 \%$ CI: $[.036, .195]$; see OSM Table 2A for the non-significant results on the other social contact items). This effect was still significant after applying Bonferroni corrections for multiple comparisons $(\alpha=.05 / 8=0.006)$. Moreover, it was corroborated by Regression 3cis that included minorities' explicitly stated number of Turkish friends as predictor of interest: Again, the more heritage culture friends, the higher minorities' heritage culture fit (step $3 R^{2}$ change $=.020, p=.016 ; B=.055, p=.016,95 \%$ CI: $[.011, .100]$; see Table 1).

Finally, we tested the associations between minorities' acculturation attitudes towards the Turkish culture and their emotional fit with the Turkish patterns (H4). Mirroring the results of Study 1, minorities' wish to maintain Turkish values and traditions was unrelated to emotional fit, but their wish to maintain social contacts with Turks' was marginally significantly associated, be it for home/family situations only (see Table 1, panel B, Regression 4; step $4 R^{2}$ change $=.028, p=.082$ ). Again, we conducted a post-hoc regression analysis to disentangle this effect of desiring social contact with heritage members from having actual contact with heritage members. Just like in Study 1, however, the effect of Attitudes towards Maintaining 
RUNNING HEAD: EMOTIONAL FIT WITH THE HERITAGE CULTURE

Social Contact with Heritage Members disappeared once we included the variables referring to actual contacts with heritage members. ${ }^{4}$ When all three contact-related items were included (step $3 R^{2}$ change $=.048, p=.004$ ), only Turkish Belgians' use of the Turkish language with friends significantly predicted their Turkish emotional fit $(B=.102, p=.013,95 \%$ CI: $[.022$, .182]; see Table 1, panel B). Turkish Belgians' fit to the typically Turkish emotional patterns is thus only associated with the extent to which they engage in actual heritage culture friendships.

Situational factor: Does interacting in Turkish cultural settings afford Turkish Belgians to fit the Turkish emotional patterns better? To test whether the situational factor Context shaped Turkish Belgians' emotional fit with their heritage culture (H5), we compared their fit with the typical Turkish versus typical Belgian emotional patterns in home/family versus work/school contexts. A Repeated Measures ANOVA with emotional fit scores as within-subjects variables and Valence, Context and Generation as between-subjects variables, provided initial support for H5. Confirming the findings reported above, this analysis yielded i) a significant within-subjects effect of Generation on Emotional Fit (Pillai's Trace $=.069$ $\left.F_{(1,130}=9.665, p=.002, \eta^{2}=.069\right)$ such that first generation minorities had a higher fit with the Turkish $(M=68, S E=.049)$ than the Belgian patterns $(M=.62, S E=.046 ;$ Mean_diff $=-.055$, $S E=.024, p=.023$ ), whereas the opposite was true for second generation minorities (Belgian fit: $M=.65, S E=.039$; Turkish fit: $M=.61, S E=.042 ;$ Mean_diff $=-.042, S E=.020, p=.038$ ), and ii) a significant between-subjects effect of Valence $\left(F_{(1,130}=159.89, p \leq .001\right)$. No other within-subject effects were significant, implying that the hypothesized three way interaction of Emotional Fit*Context*Generation also did not reach significance (Pillai's Trace $=.003 F_{(1,130}$

${ }^{4}$ Minorities' attitudes toward social contact with Turks were highly correlated with their explicit statement of having Turkish friends $(r=.435, p \leq .001)$, but uncorrelated with the more implicit measure of speaking Turkish among friends $(r=.061, p=.481)$; the latter two scales were moderately associated $(r=.171, p$ $=.047)$. 
$\left.=.440, p=.508, \eta^{2}=.003\right)$. However, as expected, the pattern of pairwise comparisons was very consistent with the trends observed in Study 1. Turkish first generation minorities were more concordant to Turkish $(M=.67, S E=.071)$ than to Belgian $(M=.61, S E=.066)$ emotional patterns in home/family contexts (Mean_diff $=.063, S E_{\text {mean diff }}=.034, p=.070$, one-tailed $p=$ $.035 ; 95 \%$ CI: $[-.005, .130])$, but did not differentiate between the patterns in work/school contexts. In contrast, second generation minorities were more concordant to Belgian $(M=.68$, $S E=.054)$ than to Turkish $(M=.60, S E=.058)$ patterns in work/school contexts $($ Mean_diff $=$ $.071, S E_{\text {mean diff }}=.028, p=.013$, one-tailed $\left.p=0.007 ; 95 \% \mathrm{CI}:[.015, .126]\right)$, but did not differentiate between Belgian and Turkish patterns at home (see Figure 2, right panel). Taken together, this set of results provides further tentative support for the idea that minorities switch cultural frames in the domain of emotions, but also suggests that the specific condition under which frame-switching occurs, may differ across first and second generation minorities.

\section{General Discussion}

The current research documents which personal and situational factors afford immigrant minorities to maintain their heritage culture's emotional patterns. It suggests that when immigrant minorities come to fit the emotional patterns typical of the new mainstream culture, they do not necessarily 'lose' their emotional concordance to their heritage culture. Rather, minorities may maintain (and perhaps even cultivate) their heritage emotional patterns through maintaining friendships with heritage culture members (personal factor) and interacting in situations that prompt and afford heritage cultural meanings and practices (situational factor). Specifically, our studies on Korean Americans and Turkish Belgians showed that minorities' emotional fit with the heritage culture was i) positively associated with their number of Korean and Turkish friends and ii) higher when interacting at home versus at school/work (although the latter was most outspoken for first generation minorities). Thus, the current studies consistently suggest that minorities' heritage culture emotional patterns are maintained (and 
perhaps even cultivated) through interacting with heritage culture friends and are most prominent (and thus activated) when it is most relevant: In contacts with other heritage members.

Before discussing these findings in detail, we will take a closer look at two other results that were not at the core of our research, but that are nevertheless important. Firstly, and replicating other studies on emotional fit with culture (De Leersnyder et al., 2011; Jasini et al., 2019), we found that fit in positive situations is significantly higher than fit in negative situations, and that this result holds true for both majority and minority members. As speculated before (De Leersnyder et al., 2011), this may be due to the fact that negative emotional situations are more complex than positive ones - something that is also reflected by the higher sum of variances of all emotion terms in the negative (73.6 in Study 1 and 79.7 in Study 2) than in the positive situations (51.6 in Study 1 and 49.2 in Study 2). Importantly, however, we found no differences with regard to the associations between the various personal factors and emotional fit in positive versus negative situations: None of the interaction effects between Valence and our predictors of interest were significant. The only exception to this was that Korean Americans' friendships with Koreans only contributed to their fit with the typical Korean patterns for negative emotional situations, and not to their fit in positive situations. One potential explanation for this is that whereas positive situations are discussed with many others, negative situations, and especially negative engaging ones (that center around shame) are mainly discussed with close friends (Rimé, Mesquita, Phillipot \& Boca, 1991). Therefore, having Korean friends may be especially important for Korean Americans to maintain fit with the typical Korean patterns in negative situations.

A second finding that was not at the core of our hypotheses, but that can shed important light on the nature of emotional fit with culture, is that immigrant minorities seemed to fit their heritage culture patterns about equally well as they fit their new majority culture patterns (De 
Leersnyder et al., 2011), while majority members only fitted to their own and not the other culture's patterns. To underpin this observation with statistics, we conducted, for each study, a post-hoc repeated measures ANOVA in which we predicted all participants' level of emotional fit with both the new mainstream (i.c., European American, Belgian) and the heritage (i.c., Korean, Turkish) typical patterns of emotion from their group membership. We found that all majority groups (Koreans, European Americans, Turks, Belgians) were significantly more concordant to their own than to another culture's emotional patterns, but that immigrant minorities' fitted both patterns about equally well (see Online Supplementary Materials for a full report). This suggests that for immigrant minorities the new mainstream and heritage culture's emotional patterns tend to co-exist.

\section{Predicting maintenance of heritage culture emotional patterns}

The current research started from the observation that most immigrant minorities engage in heritage cultural contexts on a daily basis, and clarified which aspects of heritage engagement are associated with minorities maintaining their heritage emotional patterns. Whether immigrant minorities have heritage culture friends was the only personal factor that predicted emotional fit with the heritage culture across both studies. Neither length of time spent in the country of origin nor age at immigration predicted the emotional fit with the heritage culture findings that can be understood from the fact that our minority participants (like so many other minorities) live in ethnic enclaves that expose them to (a form of) the heritage culture. Also, participants' general level of social contact with heritage members did not predict heritage emotional fit, perhaps because there is less meaningful variation in minorities' number of heritage culture family members and colleagues. The fact that it was a function of one's contact with heritage culture friends further supports the idea that friendships may play a particularly important role in the (re)negotiation of emotional meanings while sharing emotional events. 
RUNNING HEAD: EMOTIONAL FIT WITH THE HERITAGE CULTURE

Future research should further investigate these explanations by, for instance, explicitly testing to what extent i) these different indicators of heritage culture engagement are associated with the endorsement of heritage culture meanings and practices and ii) minorities actually share their emotional experiences much more with heritage culture friends than with family members, co-workers and neighbours. Relatedly, future research could further examine why having Korean friends was a predictor of Korean Americans' emotional fit to the Korean average emotional patterns for negative situations only (Study 1; see above).

Despite these remaining questions, the current research documents which aspects of minorities' engagement in the heritage culture are associated with their maintenance of heritage culture patterns and which aspects are not. In this way it contributes to a more complete understanding of emotional acculturation. The fact that the predictors of mainstream and heritage cultural fit do not mirror one another perfectly may fuel further research, and shed light on the group-level findings discussed earlier. If anything, the results show that when immigrant minorities engage in a new cultural context, they are not 'doomed to lose' their heritage culture emotional patterns, especially not when they engage in friendships with heritage culture members.

\section{Towards a situated and heterogeneous approach of acculturation}

Our findings inform acculturation psychology in several ways. Firstly, studies on acculturative changes in emotional patterns complement traditional acculturation research that has focused on minorities' attitudes and cultural identities, which are deliberate, conscious, articulate, and reflective positions towards the mainstream and heritage cultures (e.g., (Berry, 1997; Phinney, 1990; Sam \& Berry, 2010). It calls for a 'cultural psychological' approach to acculturation (see De Leersnyder, 2014; Mesquita, De Leersnyder, \& Jasini, 2019) in which all aspects of people's psychological functioning, such as their self-esteem (Heine \& Lehman, 
RUNNING HEAD: EMOTIONAL FIT WITH THE HERITAGE CULTURE

2004), self-construal (De Leersnyder, 2009), personality (Güngör et al., 2013) and emotional lives may be subject acculturation.

Secondly, the finding that emotional fit to the heritage culture was dissociated from minorities' explicit attitudes towards maintaining the heritage culture commends interpreting emotional concordance as a more implicit reflection of acculturation. Moreover, it calls for a novel view on acculturation in which different aspects of minorities' psychological functioning may acculturate at different paces or even in different directions. As found here and elsewhere (i.c. De Leersnyder et al., 2011; Jasini, et al., 2019), minorities' explicitly held (attitudes, identities) and implicitly embodied (emotions) cultural affiliations could be more heterogeneous than previously assumed.

\section{Cultural frame switching in emotions}

In addition to providing insight in (emotional) acculturation, our findings also speak to cultural frame switching (e.g., Hong et al., 2000). By showing that minorities' emotional patterns were more concordant with heritage culture patterns in situations that took place at home/with family, whereas they were more concordant with majority patterns in work/school situations, the current research provides initial additional evidence for cultural frame switching in the domain of emotions. These findings were moderated by minorities' generational status, though, with first generation minorities showing more distinct patterns of emotions at home/with family and second generation minorities showing more distinct patterns at school/work. This may be so, because first generation minorities - who grew up in the heritage country - may have a more clear picture of how emotional responses should look like in (heritage culture) family situations than in (majority) work/school situations, while the opposite may be true for second generation minorities who grew up in the new mainstream context - a speculation that needs to be addressed in future research. 
RUNNING HEAD: EMOTIONAL FIT WITH THE HERITAGE CULTURE

Nevertheless, the current findings go beyond the only other study on emotional frame switching (Perunovic et al., 2007) in several ways. Firstly, they document cultural frame switching in the patterning of emotions rather than in associations between average levels of positive and negative moods. Secondly, and most importantly, they are based on actually measured instead of inferred fit between minorities' emotions and those that are typical for the heritage and mainstream cultures. Of course, future research should address the exact differences between heritage and new mainstream emotional patterns as well as examine which contextual cues activate each of these culture's emotional patterns.

\section{Emotions}

Finally, the current studies also speak to our understanding of emotions per se. The finding that minorities continue to fit emotionally with their heritage culture upon engaging in heritage culture friendships supports the idea that people's - ongoing and multiple - cultural engagements shape their experiences to be in line with them (e.g., Mesquita, 2003; Mesquita et al., 2017). Furthermore, the initiatadditional evidence for minorities' frame switching between heritage and new mainstream patterns of emotion, can be taken as support for the idea that people construe their emotional experiences dynamically and thus 'in the moment' to be in line with the prevailing cultural context (e.g., Boiger \& Mesquita, 2012).

\section{Limitations}

The current research has some limitations. First, the sample size of Study 1 was rather small, which may have weakened the power of our analyses. Yet, as the results of Study 1 were replicated in Study 2, we have confidence that the findings can be interpreted, especially given the fact that the two case studies were maximally different yet theoretical replications from one another. Second, we calculated emotional concordance for home/family and work/school contexts as we assumed that the heritage culture is salient in home/family contexts and the majority culture is pertinent in work/school contexts. In reality, these contexts may be less 
culturally homogenous, due to people from diverse ethnic backgrounds being present at the same time, switching between different languages of interaction, and the simultaneous presence of cultural symbols that refer to the new and the heritage context. If anything, the dynamics of emotional acculturation may thus still be more complex than we outlined here.

\section{Conclusion}

In sum, the current research documented the personal and situational factors that afford immigrant minorities to maintain emotional patterns that are typical for their heritage cultural context. It suggests that minorities do not lose existing heritage emotional patterns when they acquire new mainstream emotional patterns, but can continue to maintain these patterns while interacting with heritage culture friends. In addition, it suggests that minorities may switch between heritage and new mainstream emotional patterns depending on the context of interaction: When interacting in heritage cultural settings (at home) they are more concordant to typical heritage than to typical majority emotional patterns, while the opposite is true when interacting in majority cultural settings (at work/school). As such, the current research shows that minorities' emotional patterns are not only cultivated, but also activated by their interactions in different socio-cultural contexts. 
RUNNING HEAD: EMOTIONAL FIT WITH THE HERITAGE CULTURE

\section{References}

Alba, R. (2005). Bright vs. blurred boundaries: Second-generation assimilation and exclusion in France, Germany, and the United States. Ethnic and Racial Studies (Vol. 28). http://doi.org/10.1080/0141987042000280003

Berry, J. W. (1997). Immigration, acculturation, and adaptation. Applied Psychology: An International Review, 46(1), 5-34. http://doi.org/10.1111/j.1464-0597.1997.tb01087.x

Boiger, M., Güngör, D., Karasawa, M., \& Mesquita, B. (2014). Defending honour, keeping face: Interpersonal affordances of anger and shame in Turkey and Japan. Cognition \& Emotion, 28(7), 1255-1269. http://doi.org/10.1080/02699931.2014.881324

Boiger, M., \& Mesquita, B. (2012). The construction of emotion in interactions, relationships, and cultures. Emotion Review, 4(3), 221-229. http://doi.org/10.1177/1754073912439765

Boiger, M., Mesquita, B., Uchida, Y., \& Barrett, L. F. (2013). Condoned or condemned: The situational affordance of anger and shame in the United States and Japan. Personality and Social Psychology Bulletin, 39(4), 540-553. http://doi.org/10.1177/0146167213478201

Briley, D. a., Morris, M. W., \& Simonson, I. (2005). Cultural chameleons: Biculturals, conformity motives, and decision making. Journal of Consumer Psychology, 15(4), 351362. http://doi.org/10.1207/s15327663jcp1504_9

Consedine, N. S., Chentsova-Dutton, Y. E., \& Krivoshekova, Y. S. (2014). Emotional acculturation predicts better somatic health: Experiental and expressive acculturation among immigrant women from four ethnic groups. Journal of Social and Clinical Psychology, 33(10), 867-889. https://doi.org/10.1521/jscp.2014.33.10.867

De Leersnyder, J. (2009). Turkish Belgians' Acculturation of Self-construal. Leuven. 
RUNNING HEAD: EMOTIONAL FIT WITH THE HERITAGE CULTURE

De Leersnyder, J. (2014). Emotional Acculturation. University of Leuven.

De Leersnyder, J. (2017). Emotional Acculturation: A first Review. Current Opinion in Psychology, 17, 67-73. http://doi.org/10.1016/j.copsyc.2017.06.007

De Leersnyder, J., Kim, H., \& Mesquita, B. (2015). Feeling right is feeling good: Psychological well-being and emotional fit with culture in autonomy- versus relatedness-promoting situations. Frontiers in Psychology, 6, 1-12. http://doi.org/10.3389/fpsyg.2015.00630

De Leersnyder, J., Koval, P., Kuppens, P., \& Mesquita, B. (2018). Emotions and concerns: Situational evidence for their systematic co-occurrence. Emotion, 18(4), 597-614. http://doi: 10.1037/emo0000314.

De Leersnyder, J., Mesquita, B., Kim, H., Eom, K., \& Choi, H. (2014). Emotional fit with culture: A predictor of individual differences in relational well-being. Emotion, 14(2), 241-245. http://doi.org/10.1037/a0035296

De Leersnyder, J., Mesquita, B., \& Kim, H. S. (2011). Where do my emotions belong? A study of immigrants' emotional acculturation. Personality \& Social Psychology Bulletin, 37(4), 451-63. http://doi.org/10.1177/0146167211399103

De Roover, K., Ceulemans, E., Timmerman, M. E., Vansteelandt, K., Stouten, J., \& Onghena, P. (2012). Clusterwise simultaneous component analysis for analyzing structural differences in multivariate multiblock data. Psychological Methods, 17, 100-119.

FOD Werkgelegenheid, A. en S. O. (2009). Immigratie in België: aantallen, stromen en arbeidsmarkt (De). [Immigration in Belgium: numbers, flows and labor market].

Güngör, D., Bornstein, M. H., De Leersnyder, J., Cote, L., Ceulemans, E., \& Mesquita, B. (2013). Acculturation of personality: A three-culture study of Japanese, Japanese 
RUNNING HEAD: EMOTIONAL FIT WITH THE HERITAGE CULTURE

Americans, and European Americans. Journal of Cross-Cultural Psychology. http://doi.org/10.1177/0022022112470749

Heine, S. J., \& Lehman, D. R. (2004). Move the body, change the self: Acculturative effects on the self-concept. In M. Schaller \& C. Crandall (Eds.), Psychological Foundations of Culture (pp. 305-331). Mahwah, NJ: Erlbaum.

Hong, Y. Y., Morris, M. W., Chiu, C. Y., \& Benet-Martínez, V. (2000). Multicultural minds: A dynamic constructivist approach to culture and cognition. The American Psychologist, 55(7), 709-720. http://doi.org/10.1037/0003-066X.55.7.709

Jasini, A., De Leersnyder, J., Kende, J., Gagliolo, M., Phalet, K., \& Mesquita, B. (submitted). Show me your friends, I'll tell you your emotions: Emotional acculturation of immigrant minority youth in cross-cultural friendship networks. Manuscript submitted for publication.

Jasini, A., De Leersnyder, J., Phalet, K., \& Mesquita, B. (2019). Tuning in emotionally: Associations of cultural exposure with distal and proximal emotional fit in acculturating youth. European Journal of Social Psychology. 49 (2), 352-365. https://doi.org/10.1002/ejsp.2516

Kitayama, S., \& Imada, T. (2010). Implicit independence and interdependence: A cultural task analysis. In B. Mesquita, L. F. Barrett, \& E. R. Smith (Eds.), The mind in context (pp. 174200). New York, NY: Guilford.

Kitayama, S., Mesquita, B., \& Karasawa, M. (2006). Cultural affordances and emotional experience: Socially engaging and disengaging emotions in Japan and the United States. Journal of Personality and Social Psychology, 91(5), 890-903. http://doi.org/10.1037/0022-3514.91.5.890 
RUNNING HEAD: EMOTIONAL FIT WITH THE HERITAGE CULTURE

Kosic, A., \& Phalet, K. (2006). Ethnic categorization of immigrants: The role of prejudice, perceived acculturation strategies and group size. International Journal of Intercultural Relations, 30(6), 769-782. http://doi.org/10.1016/j.ijintrel.2006.06.003

LaFromboise, T., Coleman, H., \& Gerton, J. (1993). Psychological impact of biculturalism: Evidence and theory. Psychological Bulletin, 114, 395-412.

Markus, H. R., \& Kitayama, S. (1991). Culture and self: Implications for cognition, emotion, and motivation. Psychological Review 98, 224-253. https://doi.org/10.1037/0033295X.98.2.224.

Mesquita, B. (2001). Emotions in Collectivist and Individualist Contexts. Journal of Personality and Social Psychology, 80(1), 68-74. DOI: 10.1037//0022-3514.80.1.68

Mesquita, B. (2003). Emotions as dynamic cultural phenomena. In R. J. Davidson, K. R. Scherer, \& H. H. Goldsmith (Eds.), Handbook of affective sciences (pp. 871-890). Oxford: Oxford Univeristy Press.

Mesquita, B., Boiger, M., \& De Leersnyder, J. (2016). The cultural construction of emotions. Current Opinion in Psychology, 8, 31-36. http://doi.org/10.1016/j.copsyc.2015.09.015

Mesquita, B., Boiger, M., \& De Leersnyder, J. (2017). Doing Emotions: The Role of Culture in Everyday Emotions. European Review of Social Psychology, 28 (1), 95-133. https://doi.org/10.1080/10463283.2017.1329107.

Mesquita, B., De Leersnyder, J., \& Jasini, A. (2019). The Cultural Pscyhology of Acculturation. In S. Kitayama \& D. Cohen (Eds.), Handbook of cultural Psychology (2 nd). New York, NY: Guilford Press.

Perunovic, W. Q. E., Heller, D., \& Rafaeli, E. (2007). Within-person changes in the structure 
RUNNING HEAD: EMOTIONAL FIT WITH THE HERITAGE CULTURE

of emotion: The role of cultural identification and language. Psychological Science, 18(7), 607-13. http://doi.org/10.1111/j.1467-9280.2007.01947.x

Phinney, J. S. (1990). Ethnic identity in adolescents and adults: Review of research. Psychological Bulletin, 10(3), 499-514. DOI: 10.1037/0033-2909.108.3.499.

Ramírez-Esparza, N., Gosling, S. D., Benet-Martínez, V., Potter, J. P., \& Pennebaker, J. W. (2006). Do bilinguals have two personalities? A special case of cultural frame switching. Journal of Research in Personality, 40(2), 99-120. http://doi.org/10.1016/j.jrp.2004.09.001

Rimé, B., Mesquita, B., Phillipot, P., \& Boca, S. (1991). Beyond the emotional event: Six studies on the social sharing of emotion. Cognition and Emotion, 5 (5/6), 435-465. https://doi.org/10.1080/02699939108411052.

Rothbaum, F. M., Pott, M., Azuma, H., Miyake, K., \& Weisz, J. R. (2000). The development of close relationships in Japan and the United States: Paths of symbiotic harmony and generative tension. Child Development, 71(5), 1121-1142. DOI: 10.1111/14678624.00214.

Ryder, A. G., Alden, L. E., \& Paulhus, D. L. (2000). Is acculturation unidimensional or bidimensional? A head-to-head comparison in the prediction of personality, self-identity, and adjustment. Journal of Personality and Social Psychology, 79(1), 49-65. http://doi.org/10.1037//0022-3514.79.1.49

Sam, D. L., \& Berry, J. W. (2010). Acculturation: When individuals and groups of different cultural backgrounds meet. Perspectives on Psychological Science, 5(4), 472-481. http://doi.org/10.1177/1745691610373075

Schwartz, S. J., Unger, J. B., Zamboanga, B. L., \& Szapocznik, J. (2011). How selective is 
RUNNING HEAD: EMOTIONAL FIT WITH THE HERITAGE CULTURE

acculturation? Broadening our perspective. American Psychologist, 66(2), 155-157. http://doi.org/10.1037/a0022560

Snauwaert, B., Soenens, B., Vanbeselaere, N., \& Boen, F. (2003). When integration does not necessarily imply integration: Different conceptualizations of acculturation orientations lead to different classifications. Journal of Cross-Cultural Psychology, 34(2), 231-239. http://doi.org/10.1177/0022022102250250

Terrazas, A. (2009). Korean Immigrants in the United States. Retrieved from Migration Policy Institute website: http://www.migrationinformation.org/USfocus/display.cfm? ID=716.

Tsai, J. L., Knutson, B., \& Fung, H. H. (2006). Cultural variation in affect valuation. Journal of Personality and Social Psychology, 90(2), 288-307. http://doi.org/10.1037/00223514.90.2.288

Van Acker, K. (2012). Flanders' real and present threat. How representations of intergroup relations shape attitudes towards Muslim minorities. Unpublished doctoral dissertation, University of Leuven, Leuven, Belgium.

van den Broek, A., \& van Ingen, E. (2008). Sociale contacten in de vrije tijd [Social contacts in leisure time]. In A. van den Broeck \& S. Keuzenkamp (Eds.), Het dagelijks leven van allochtone stedelingen [The daily life of ethnic minority citizens] (pp. 101-124). Den Haag: Sociaal en Cultureel Planbureau.

Verkuyten, M., \& Pouliasi, K. (2002). Biculturalism among older children: Cultural frame switching, attributions, self-identification, and attitudes. Journal of Cross-Cultural Psychology, 33(6), 596-609. http://doi.org/10.1177/0022022102238271

Yoo, D., \& Chung, R. H. (2009). Religion and spirituality in Korean America. Urbana: University of Illinois Press. 